\title{
A review of the LATEX project: mesoscale to submesoscale processes in a coastal environment.
}

\author{
A.A. Petrenko • A.M. Doglioli • \\ F. Nencioli • M. Kersalé • Z.Y. Hu • \\ F. d'Ovidio \\ 7 the date of receipt and acceptance should be inserted later
}

8 Abstract The main objective of the LAgrangian Transport EXperiment (LA9 TEX) project was to study the influence of coastal mesoscale and submesoscale 10 physical processes on circulation dynamics, cross-shelf exchanges and biogeo1 chemistry in the western continental shelf of the Gulf of Lion, Northwestern 12 Mediterranean Sea. LATEX was a five-year multidisciplinary project based on 3 the combined analysis of numerical model simulations and multi-platform field 14 experiments. The model component included a ten-year realistic 3D numer15 ical simulation, with a $1 \mathrm{~km}$ horizontal resolution over the gulf, nested in a 16 coarser $3 \mathrm{~km}$ resolution model. The in situ component involved four cruises, 17 including a large-scale multidisciplinary campaign with two research vessels 18 in 2010. This review concentrates on the physics results of LATEX, address19 ing three main subjects: 1) the investigation of the mesoscale to submesoscale

A.A.Petrenko

Aix Marseille Université, Université de Toulon, CNRS, IRD, Mediterranean Institute of Oceanography (MIO), Marseille, France

Tel.: +00(33)4 86090606

E-mail: anne.petrenko@mio.osupytheas.fr

A.M.Doglioli

Aix Marseille Université, Université de Toulon, CNRS, IRD, Mediterranean Institute of Oceanography (MIO), Marseille, France

F. Nencioli

Remote Sensing Group, Plymouth Marine Laboratory, Plymouth, Great Britain

M. Kersalé

Department of Oceanography, Marine Research Institute, University of Cape Town, Rondebosch, South Africa

Z.Y. Hu

Jiaozhou Bay Marine Ecosystem Research Station, Institute of Oceanology, Chinese Academy of Sciences, Qingdao, Chin

F. d'Ovidio

Sorbonne Université (UPMC, Paris 6)/CNRS/IRD/MNHN, Laboratoire d'Océanographie et du Climat (LOCEAN), Institut Pierre Simon Laplace (IPSL), Paris, France 
processes. The eddies are elliptic, baroclinic and anticyclonic; the strong thermal and saline front is density-compensated. Their generation processes are studied; 2) the development of sampling strategies for their direct observations. LATEX has implemented an adaptive strategy Lagrangian tool, with a reference software available on the web, to perform offshore campaigns in a Lagrangian framework; 3 ) the quantification of horizontal mixing and cross-shelf exchanges. Lateral diffusivity coefficients, calculated in various ways including a novel technique, are in the range classically encountered for their associated scales. Cross-shelf fluxes have been calculated, after retrieving the near-inertial oscillation contribution. Further perspectives are discussed, especially for the ongoing challenge of studying submesoscale features remotely and from in situ data.

Keywords mesoscale $\cdot$ submesoscale $\cdot$ Lagrangian · Gulf of Lion · Northwestern Mediterranean Sea $\cdot$ cross-shelf flux

\section{Introduction}

16 Coastal waters, in spite of their small surfaces and volumes (8\% and $0.05 \%$ of 17 the global ocean, respectively), are currently the object of crucial questions.

${ }_{18}$ This environment is the link between the continents, highly impacted by human presence and activities (40\% of the world population lives less than 100 $\mathrm{km}$ from the coast) and the ocean, one of the main regulators of the global thermal and biogeochemical cycles. The coastal zone is usually characterized by high biological productivity due to a large availability in nutrients coming from human and river inputs. Thus coastal areas contribute to an important part of the carbon sequestration in the ocean and play a key role in climate change. Moreover, coastal dynamics have strong ecological repercussions, such as the regulation of biogeochemical cycles through local circulation and cross-shelf exchanges, as well as the dispersion of larvae and pollutants through current advection. Coastal physical processes also influence higher trophic levels having, for example, repercussions for fisheries. Their understanding is therefore of critical importance for sustainable management of the marine environment. Among coastal physical processes, mesoscale and submesocale -hereafter referred to as (sub)mesoscale- processes have a particularly important role.

(Sub)mesoscale processes are ubiquitous in the open ocean, as well as in coastal waters. They have spatial scale of the order of few kms and temporal scales of days to weeks, hence they are typically localized and ephemeral. On one hand, mesoscale processes are generally produced by the instability of large scale currents (McWilliams et al., 1983, Robinson, 1983). They are in approximate geostrophic balance in the horizontal and hydrostatic balance in the vertical, and are characterized by small Rossby and Froude numbers (Cushman-Roisin, 1994). Thus, their dynamics are predominantly horizontal. Submesoscale processes, on the other hand, usually arise from instabilities in the mixed layer due to mesoscale-induced stirring, wind forcing, or a combination of the two (e.g. Thomas et al. 2008). They are characterized by 
$1 \mathcal{O}(1)$ Rossby and Richardson numbers. Thus, they are typically ageostrophic, and their dynamics markedly 3D. They can generate non negligible vertical motion and enhance local mixing. Hence submesoscale processes can have an important biogeochemical impact by supplying nutrients both vertically and laterally (Moore II et al., 2007, Suthers et al., 2011, Mahadevan, 2016). Length scales of mesoscale oceanic processes in coastal area are usually of $\mathcal{O}(10-100)$ $\mathrm{km}$, while those of submesoscale processes of $\mathcal{O}(0.1-10) \mathrm{km}$. (Sub)mesoscale processes such as coastal eddies, fronts and filaments are particularly important for coastal environments since they are key contributors to the energy budget, tracer transport and biogeochemical cycles. This Review focuses on the first two contributions.

Coastal eddies have generally been related to strong currents, mixed layer stratification and/or wind forcing (Mitchelson-Jacob and Sundby, 2001), outflows of coastal waters (Crawford, 2002 Di Lorenzo et al., 2005), flow instabilities along the continental slope (Melson et al. $1999 \mid$ Flexas et al., 2002), topographic forcing (MacFadyen et al. | 2008 | Staneva et al. | 2001), upwelling processes (MacFadyen and Hickey, 2010) or transfers of energy from other eddies (Garreau et al., 2011).

Fronts are regions characterized by strong horizontal gradients of hydrographic properties (temperature, salinity or both). Typically, the variations of a parameter across the front axis are an order of magnitude larger than changes of this parameter over the same distance on either side of the front. If the horizontal gradients of temperature and salinity are also associated with variations in density, the front is named a density front. While if the horizontal temperature gradient is balanced by that of salinity, so that the resulting cross-front density profile is almost constant, the front is called density-compensated. Fronts are linked to mesoscale dynamics because they are often created by mesoscale-induced stirring, although other processes can also generate them: e.g. tides, atmospheric forcing, freshwater inputs. They can also be linked to submesoscale dynamics, because the front's development often leads to, or is associated with the formation of $3 \mathrm{D}$ secondary ageostrophic circulation (Thomas et al., 2008, Capet et al., 2008b).

Coastal eddies and fronts have a strong influence on horizontal ocean mixing and, hence, could impact diffusivity. In the past, in situ estimates of lateral diffusivity at scales smaller than $100 \mathrm{~km}$ have been most commonly obtained from passive tracer (e.g. sulfur hexafluoride, $S F_{6}$ ) experiments. Such estimates are based on the hypothesis that, under local mesoscale stirring (which can be approximated, to a first order, as 2D and hence divergence-free), the width of the patch decreases until the effects of mesoscale stirring are balanced by smaller scale diffusion and an equilibrium is reached. Thus, lateral diffusivity can be computed by combining estimates of the strain rate (usually estimated from successive in situ mappings Ledwell et al. 1998, or from the analysis of satellite imagery of surface tracers, Abraham et al. 2000) with in situ measurements of the patch width. Lateral diffusivities computed using this approach range from 0.5 to $25 \mathrm{~m}^{2} \mathrm{~s}^{-1}$ for tracer filaments with widths between 1 and $10 \mathrm{~km}$. At similar scales but in less energetic systems, lateral diffusivities have 
1 also been estimated by neglecting the strain and measuring the growth of the roughly circular tracer patch (e.g. the Santa Monica Basin Tracer Experiment, Ledwell and Watson 1991, and the BATRE experiment, Holtermann et al. 2012). Following this method, the lateral diffusivities were of the order of $10 \mathrm{~m}^{2} \mathrm{~s}^{-1}$ for the interior of the two basins at scales on the order of $10 \mathrm{~km}$.

Eddies and fronts can also have an important role on cross-shelf exchanges. In the last decades, cross-shelf exchanges have been the focus of several studjes (Brink and Cowles, 1991, Biscaye, 1994, Huthnance et al., 2002; Johnson and Chapman, 2011). Continental shelves are often bounded by strong largescale (geostrophic) currents flowing along the steep bathymetry of the shelf edge (Huthnance, 1995). These tend to inhibit cross-shelf exchanges which, therefore, are mainly enabled by localized, mostly short-lived and predominantly ageostrophic events, such as internal tide breaking (Hopkins et al. 2012), Ekman transport (Kirincich and Barth, 2009), dense shelf water cascading (Canals et al., 2006), eddies (Capet et al., 2008a Nagai et al. 2015), mesoscale-stirred fronts (Ferrari, 2011) and filaments (Nagai et al. | 2015). Estimates of the net fluxes induced by these processes remain hard to quantify from in situ observations due to the temporal and spatial scales of the processes involved (Huthnance et al. 2009). In global models, the effect of (sub)mesoscale processes is still parametrized (e.g. eddy viscosities and diffusivities). Indeed, despite some recent advancements towards (sub)mesoscale resolving resolutions, they usually cannot properly resolve their associated dynamics. Nonetheless, (sub)mesocale processes can now be accurately resolved by high-resolution regional numerical models. Therefore, the impact of these processes on coastal environments and cross-shelf exchanges has been investigated at the regional scale mainly through the analysis of numerical simulations with relatively rare concomitant observations for comparisons (Burchard et al. 2008, Capet et al. 2008a b). For these reasons, direct observations of (sub)mesoscale processes still represent a key and much-needed component for the further advancement of both regional and global models.

The main objective of the LAgrangian Transport EXperiment (LATEX) project was to study the influence of coastal (sub)mesoscale physical processes on circulation dynamics, cross-shelf exchanges and biogeochemistry in the western continental shelf of the Gulf of Lion (GoL), Northwestern Mediterranean sea (Fig. 1). LATEX was a five-year (2007-2011) multidisciplinary project based on the combined analysis of numerical model simulations and multi-platform field experiments.

The GoL is a large continental shelf, approximately the shape of a semicircle with a radius near $100 \mathrm{~km}$, and a surface area of about $11000 \mathrm{~km}^{2}$. The main forcings of the shelf circulation include: (i) the strong northerly and northwesterly continental winds (the Mistral and the Tramontane); (ii) the Northern Current (hereafter NC) which represents the northern branch of the large-scale cyclonic circulation of the western Mediterranean basin, flowing along the continental slope from the Ligurian Sea to the Catalan Sea (Millot 1990); (iii) the Rhône River which is the main fresh water source of the GoL. 
A general description of the hydrodynamics of the GoL is provided by Millot (1990). The existence of an anticyclonic circulation in the western part of the gulf following upwelling phenomena and an offshore drift of surface water has been first hypothesized in Millot (1979, 1982). Later, Estournel et al. (2003) showed an anticyclonic eddy located at the center of the GoL continental shelf or an anticyclonic circulation covering the western and center parts of the GoL, using both observations and model. On the eastern part of the GoL continental shelf, eddies are generated by the local wind (Allou et al., 2010 Schaeffer et al. 2011). (Sub)mesoscale processes are quite active also offshore the GoL, where submesoscale coherent vortices can be formed in regions of deep convection (Bosse et al., 2016).

The GoL is particularly appropriate for studying coastal mesoscale dynamics and its role in regulating cross-shelf exchanges. Before the LATEX campaigns, two processes were recognized as main contributors to the exchanges between the GoL and offshore waters: dense shelf water cascading (Durrieu et al. 2013, Canals et al., 2006) and more shallow processes associated with the NC (Millot and Taupier-Letage, 2005). Intrusions of the NC on the continental shelf of the GoL have been studied in the western (Millot and Wald 1980; Petrenko et al., 2008), central (Estournel et al., 2003 Petrenko, 2003) and eastern parts (Petrenko et al. 2005 Barrier et al. 2016) of the GoL. On the eastern side, the flux of some of these intrusion events were estimated with in situ data, ranging between $0.37 \mathrm{~Sv}$ (Petrenko et al., 2013) and 0.5 Sv (Petrenko et al. 2005). By 2006, some (sub)mesoscale processes had been identified and studied on the eastern side of the GoL (Petrenko et al., 2005) and in its central region, especially linked to the Rhône river plume (Naudin et al. 1997; Broche et al. 1998). However, in the western part of the GoL, the focus had been mainly on dense water formation (Durrieu De et al. 2005), while smaller scale processes had been relatively poorly investigated. The LATEX project aimed at filling this gap, addressing -in its physics componentthree main questions:

- What are the generation mechanisms and the general characteristics of (sub)mesoscale processes in the western GoL?

- How can field experiments be designed to investigate coastal (sub)mesoscale structures?

- How much horizontal mixing and cross-shelf exchanges are associated with these processes?

After a brief introduction to the LATEX project (section 2), this review will provide answers to these questions. Each question will be addressed in one specific section: dynamics in the western GoL (section 3), in situ sampling strategies (section 4), calculation of horizontal mixing and exchanges (section 51. Finally, the Conclusion and Perspectives are drawn in section 6 and 7. respectively. 


\section{Data and Methods}

2 Numerical model simulations and in situ observations from a series of field

3 experiments enabled us to answer the three main questions raised above.

\section{$4 \quad 2.1$ Numerical modeling}

5 The LATEX project included a numerical component whose initial objective, during the pilot phase, was to study the probability of occurrence of stable mesoscale structures in the $\mathrm{GoL}$ ( $\mathrm{Hu}$ et al. 2009). Once this was positively achieved, the modeling component aimed at two main objectives: 1) to investigate the mechanism of formation and the characteristics of these structures; 2 ) to provide additional information to integrate/complement the analysis from in situ observations.

The model used in the project was Symphonie (Marsaleix et al. 2006 2008), a 3D primitive equation, free surface, sigma coordinate ocean model, based on the Boussinesq and hydrostatic approximations. Components of current, temperature and salinity are computed on an Arakawa-C grid using a classic finite difference method. The vertical turbulence closure is achieved through a prognostic equation for the turbulent kinetic energy and a diagnostic equation for the mixing and dissipation length scales (Gaspar et al., 1990). As part of the pilot LATEX project in 2007, an optimized configuration of the Symphonie model was established for the Northwestern Mediterranean Sea $(3 \mathrm{~km}$ resolution $)$, with a nested high-resolution $(1 \mathrm{~km})$ model in the GoL $(\mathrm{Hu}$ et al. 2009). The high-resolution model domain is shown in Fig. 1

Using this configuration, a realistic simulation was performed over 10 years, from 2001 to 2010. The initial and open boundary conditions for the larger domain were provided by the Mediterranean Forecasting System (MFS, http:// eurogoos.eu/member-product/mediterranean-ocean-forecasting-system/ general circulation model (Pinardi, 2003) with a resolution of $1 / 8^{\circ}$. The atmospheric forcing was obtained from the 3 -hr outputs of the meteorological model Aladin of Météo-France with a spatial resolution of $0.1^{\circ} \times 0.1^{\circ}$. The daily fresh water fluxes from the major rivers were taken into account. No data assimilation was included in the simulation. The readers are referred to Hu et al. (2009, 2011a) for more details about the model settings.

The simulation was used to characterize the stable mesoscale processes in the western part of the GoL. The utility program WATERS (Doglioli et al. 2007 ) was used to objectively identify and follow coherent eddy structures. The method is based on wavelet analysis of horizontal slices of modeled relative vorticity. It detects the contour and the center of a coherent structure and monitors its characteristics over time and space. The numerical outputs also provided information on the larger scale dynamical context of the processes taking place before, during and after the field cruises. 
$1 \quad 2.2$ Satellite derived products

2 Satellite data include SeaWiFs chlorophyll concentration (from NASA Goddard Space Flight Center) and a pseudo-SST (Sea Surface brilliance Temperature provided by Météo-France and corresponding to channel 4 of the AVHRR sensor: Advanced Very High Resolution Radiometer). These were used to identify, and follow in time, the signatures of the (sub)mesoscale processes in chlorophyll concentration and temperature. Surface geostrophic velocities produced by Ssalto/Duacs (Ssalto:, ground Segment for multi-missions of altimetry, orbitography and precise location, Duacs: Developing use of altimetry for climate studies, $1 / 8^{\circ}$ resolution over the Mediterranean basin) and distributed by AVISO, with support from CNES (AVISO: Archiving, Validation and Interpretation of Satellite Oceanographic data, CNES: French National Center for Spatial Studies, http://www.aviso.altimetry.fr/duacs/) were used for Finite Size Lyapunov Exponent (FSLE) analysis. Detailed description of the processing and corrections of AVISO satellite altimetry can be found in the Ssalto/Duacs User Handbook (2010).

Along with Finite Time Lyapunov Exponents (FTLEs) (Haller and Yuan 2000), FSLEs (Aurell et al., 1997) have recently emerged as a powerful Lagrangian diagnostic for the investigation of the dispersion properties of a flow. Both methods measure the separation rate of the trajectories of close initial particles, and can be applied for two complementary goals: quantifying dispersion processes (Waugh and Abraham, 2008, Haza et al., 2010, Lumpkin and Elipot, 2010, Schroeder et al., 2011)), or mapping Lagrangian Coherent Structures (LCSs) (Haller and Yuan, 2000 d'Ovidio et al., 2004, Olascoaga et al. 2006; Lehahn et al., 2007, Beron Vera et al. | 2008 Haller, 2011). Repulsive and attractive LCSs are associated with hyperbolic points of the flow, and provide direct information on transport and mixing patterns (Mancho et al. 2008): particles spread while moving toward hyperbolic points along repelling LCSs, whereas they aggregate while moving away from hyperbolic points along attracting LCSs, which thus represent transport barriers (Lehahn et al. 2007, Haller, 2011). The spatial organization of these structures has a large impact on the coastal environment, not only because they influence the dispersion of any tracer in the water, but also because, by separating dynamically distinct regions of the flow, they can define fluid dynamical niches which contribute to the structuring of marine ecosystems (d'Ovidio et al. , 2010) and top predator distribution (Tew Kai et al., 2009, Cotté et al., 2011, De Monte et al. 2012). Generally this altimetry based approach is less reliable in coastal regions, where the different ageostrophic dynamics induced by boundaries and nearshore forcings (Csanady, 1982), insufficient sampling, presence of land mass and inaccuracy of geophysical corrections (Bouffard et al., 2008) represent critical limiting factors for altimetry. For this reason, during the campaign of September 2010 (see section 2.3), daily maps of FSLEs were produced from real-time maps of absolute dynamic topography as a first guess of transport barriers and frontal systems, which were then precisely located by an adaptive strategy. The altimetry-derived FSLE maps, used in Nencioli et al. (2011. 
12013,2016 ) and in this current review paper, were re-processed after the campaign using the delayed-time maps of absolute topography. The near-real time and delayed-time products did not show large differences in the study area.

$4 \quad 2.3$ Field experiments

5 The LATEX project involved four cruises:

- Latex00, a preliminary three-day test cruise (June 9-11, 2007), (Petrenko 2007);

- Latex08, a one-week cruise to study an eddy (Sept. 1-6, 2008), (Petrenko 2008);

- Latex09, a one-week cruise dedicated to study another eddy (Aug. 25-30, 2009), (Petrenko, 2009);

- Latex10, a tracer, multidisciplinary cruise conducted from two R/Vs (Sept. 1 - 24, 2010), (Petrenko, 2010).

Note that, in the nomenclature for the cruises: LatexYY, YY indicates the year of the cruise for the second to the fourth cruise. The initial pilot cruise kept its original official name: Latex00, despite having taken place in 2007.

Latex08 \& Latex09 - These two LATEX field cruises focused on the detection and study of coastal mesoscale structures ( $\mathrm{Hu}$ et al., 2011b; Kersalé et al. 2013). They took place on board the R/V Téthys II. A VMBB-150 KHz shipbased Acoustic Doppler Current Profiler (ADCP) was used to measure current velocities every 4 meters down to $247 \mathrm{~m}$ depth (see Petrenko et al. 2005 for details). At chosen stations, profiles were collected using a SeaBird SBE 19 conductivity-temperature-depth (CTD) sensor. During Latex08, since the sea state did not allow use of the CTD, temperature profiles were obtained by using XBTs (eXpendableBathyThermographs). In addition, sea surface temperature, salinity, and fluorescence were measured continuously at the surface by the ship thermosalinograph SBE 21 . Wind was measured at $10 \mathrm{~m}$ above the surface. Technocean Surface Velocity Program (SVP) subsurface drifters, equipped with a $6 \mathrm{~m}$ long holey-sock drogue extending between $12 \mathrm{~m}$ and $18 \mathrm{~m}$, were deployed in the eddy to track the fluid motion at $15 \mathrm{~m}$ depth. Drifter positions were provided by the Argos system in quasi-real-time.

Latex00 \& Latex10 - These other two LATEX field campaigns were dedicated to a tracer release experiment.

The first one, Latex00, was part of a pilot project which aimed to demonstrate the feasibility of our Lagrangian methodology and of a $S F_{6}$ tracer experiment in the GoL. To our knowledge, at the time of LATEX, only one $S F_{6}$ tracer experiment had taken place in a coastal environment (Wanninkhof et al. 1997). $S F_{6}$ is a gaseous electrical insulator with a very low solubility in seawater, which results in a background concentration in the seawater of about 0.3 fmol $l^{-1}$ (fmol $\left.=10^{-15} \mathrm{~mol}\right) . S F_{6}$ can be detected at these low concentrations 
1 using the high sensitivity of gas chromatography with an electronic capture detector (Law et al. 1994). During Latex00, the background concentrations of $S F_{6}$ were measured in the surface mixed layer of the GoL. The values were around $1.35 \mathrm{fmol} \mathrm{l}^{-1}$, which is the concentration of $S F_{6}$ expected for seawater in equilibrium with the atmosphere. Therefore, during the Latex10 cruise, it was possible to use a volume of $4 \mathrm{~m}^{3}$ of seawater saturated with $S F_{6}$ to release a patch of $50 \mathrm{~km}^{2} \times 50 \mathrm{~m}$, with $S F_{6}$ concentrations roughly 200 times higher than the background value.

The main goal of the last field experiment, Latex10, was to analyze the transport patterns and dispersion rates induced by a mesoscale structure within the Lagrangian reference frame associated with it. Therefore, the experiment was designed to combine the release of $S F_{6}$ with the deployment of an array of Lagrangian buoys. Latex10 involved the coordination of two R/Vs, one (the $R / V$ Le Surôt) dedicated to the $S F_{6}$ experiment and the other one (the $R / V$ Téthys $I I$ ) dedicated to the survey of the underlying (sub)mesoscale processes. To successfully monitor such processes, the sampling strategy of the $R / V$ Téthys $I I$ was routinely optimized and adapted (hence "adaptive strategy") in a Lagrangian framework based on the near-real time analysis of all the available in situ, remote or modeled data (see also section 4). In situ measurements collected by the $R / V$ Téthys $I I$ were similar to the ones during Latex09 (see above). In addition, turbulence profiles, down to $50 \mathrm{~m}$, were acquired with a SCAMP (Self-Contained Autonomous Microstructure Profile). Lagrangian SVP subsurface drifters were released from both the $R / V$ Téthys $I I$ and the $R / V$ Le Suroit. Some were captured afterwards in order to be redeployed according to the near real-time analysis of LCSs (see Nencioli et al. (2011) for more details). The tracer release and mapping were performed from the $R / V$ Le Surôt. The strategy was defined in coordination with the $R / V$ Téthys $I I$ based on the Lagrangian navigation software (see subsection 4.3). On the $R / V$ Le Surôt, a VMBB-150 KHz hull-mounted ADCP provided current velocities every 8 meters when depth was superior to $300 \mathrm{~m}$ or every 4 meters in shallow waters. As on the $R / V$ Téthys $I I$, the $R / V$ Le Suroît thermosalinograph measured surface temperature, salinity and fluorescence along the ship transects. Wind was measured at $18 \mathrm{~m}$ above the surface. Numerous biogeochemical and biological measurements were also collected by the $R / V$ Le Suroît, but their analysis is beyond the scope of this physics review paper. Up to three gliders were coordinated (L. Mortier and P. Testor, LOCEAN, Paris; L. Beguery, DT INSU, La Seyne sur Mer, France) to circulate in the zone at the time of the study. Their positions, and derived current velocities along their routes, were sent in near real-time to the two R/Vs to provide a global view of the general circulation around the study area. The analysis of the current, temperature and salinity fields produced by the MFS was also sent to the $R / V$ Téthys $I I$ to be taken into account in the adaptive strategy. The interested reader can refer to the two Latex10 cruise reports for additional details (available on

WwW.mio.univ-amu.fr/LATEX Publications section). 


\section{Dynamics in the western GoL}

2 The numerical simulations showed that mesoscale structures were common in the western part of the GoL during stratified conditions. Structures that last more than 15 days were qualified as "long-life" (Hu et al., 2011a). This limit of 15 days was chosen after several sensitivity tests. It represents a typical scale below which, in this coastal area and during stratified conditions, structures are considered submesoscale both temporally and spatially. All long-life features were anticyclonic baroclinic eddies. The results from the numerical simulation were then further investigated to better understand the generation processes and characteristics of these eddies.

The most common process of generation (Hu et al. $2011 \mathrm{a}$ ) is due to a combined effect of wind forcing and topography, involving upwelling (south of Cape d'Agde) and Ekman transport southwestward (Fig. 2). These last two processes are generally due to strong northwest (NW) wind bursts, lasting more than 3 days. Once an eddy is created, strong stratification allows for a better transfer of wind-induced potential energy to eddy kinetic energy. However, additional strong wind bursts are also required to sustain the eddy in size and intensity. All details about the strength and persistence of the wind forcing can be found in $\mathrm{Hu}$ et al. (2011a). The level of stratification was estimated from the Symphonie numerical output by calculating the absolute value of potential energy anomaly, $\phi$, throughout the water column of the eddy generation area (hatched area on Fig. 1). $\Phi$ was shown to be a good indicator of the water column stability ( $\mathrm{Hu}$ et al. 2011a, De Boer et al. 2008, Burchard and Burchard, 2008). The more stratified the water column, the higher the value of $\phi$. The reader can refer to $\mathrm{Hu}$ et al. (2011a) for more details on this calculation. Over the ten year simulation (Fig. 3), the stratified conditions were classified into three major categories, according to the range of $\phi$ :

1. a weak stratification with a value of $\phi$ below $20 \mathrm{~J} \mathrm{~m}^{-3}$, as during the winter-spring season;

2. an intermediate stratification with a value of $\phi$ around $60 \mathrm{~J} \mathrm{~m}^{-3}$; as during early May and late October for all years between 2001 and 2010, along with summers 2002 and 2004;

3. a strong stratification with a value of $\phi$ reaching $100 \mathrm{~J} \mathrm{~m}^{-3}$, as during all summer seasons except in 2002 and 2004.

When stratification is not high enough, an eddy can be generated but it does not last longer than the time threshold of 15 days, and is classified as transient. The most stratified conditions are observed during the months of July to October (Fig. 3) and coincide with the occurrence of all the long-life eddies modeled in the GoL.

A second generation process has also been identified (Kersalé et al. 2013). This other process requires the presence of a $\mathcal{O}(100 \mathrm{~km})$ anticyclonic circulation $\left(3^{\circ}-4^{\circ} \mathrm{E}\right.$ and $\left.42^{\circ}-43^{\circ} \mathrm{N}\right)$ and a strong meandering of the NC (Fig. 4). The NC pushes the anticyclonic structure towards the coast, squeezing it so that it finally splits into two structures. The northern one, an anticyclonic barotropic 
1 eddy similar to the wind-induced eddies previously described, remains in its area of formation over the continental shelf. The southern structure, on the other hand, does eventually migrate southward to the Catalan basin, contributing to the cross-shelf exchanges described in more detail in section 5.2

According to the daily numerical outputs, 11 long-life anticyclonic eddies have occurred during the 10-year period of the simulation (Fig. 5). They are present only during the stratified period from July to October of a given year. The mean duration of these eddies is 44.5 days (with a standard deviation of 20 days), which is long in a rapidly-varying coastal environment such as the GoL. Among these 11 vortices, only one was formed by the second process (Kersalé et al. 2013), while the other 10 are explained by the first generation process (Hu et al. , 2011a). Throughout the years, the eddies occurred as follows:

- years without eddies $(2004,2007)$,

- years with 1 eddy (2001, 2002, 2006, 2008 and 2010),

- years with 2 eddies (2003, 2005 and 2009).

Hereafter vortices are called LatexA(i)_YY, with an A to specify that the eddy is anticyclonic, and potentially an i to indicate that this is the i-th eddy of year YY for the years with more than one eddy.

The years 2004 and 2007 stand out as unusual because they had no long-life eddy. In 2004, transients eddies appeared but no long-life eddy ever occurred despite successive strong NW wind events, probably due to the weakness of the summer stratification (Fig. 3). In 2007, since the stratification was strong and the wind forcing was particularly intense, the mesoscale eddy increased in scale and became an anticyclonic circulation larger than the study area (see Figure 4 of Hu et al. (2011a)). Furthermore, a third year was also found to be anomalous. In 2002, a long-life eddy existed despite an intermediate level of stratification (Fig. 3). This occurred because, as in 2007, the wind forcing was particularly strong, persistent and frequent.

Numerical model results have been complemented with in situ observations from the Latex08 and Latex09 campaigns to study the characteristics of these structures (Figure 6). Both datasets showed that these eddies are baroclinic, mainly confined within the mixed layer depth (about $30 \mathrm{~m}$ ), and generally elliptical (Hu et al. 2011a Kersalé et al., 2013). They have a diameter of about $20 \mathrm{~km}$ and tangential speed of the order of $0.3-0.4 \mathrm{~m} \mathrm{~s}^{-1}$ on the outer edge so that a full loop around the eddy takes $\sim 3$ days. When possible, the characteristics of the modeled eddies were compared with those measured and showed very good agreement ( $\mathrm{Hu}$ et al. 2011 a Kersalé et al. 2013$)$. For instance, the characteristics of the second long-life anticyclonic eddy of 2009, hereafter LatexA2_09, were compared. The center of the eddy was estimated at $3^{\circ} 26^{\prime} \mathrm{E}$ - $42^{\circ} 36^{\prime} \mathrm{N}$ in the model and at $3^{\circ} 34^{\prime} \mathrm{E}-42^{\circ} 33^{\prime} \mathrm{N}$ from in situ velocity crosssections of the eddy (see Section 4.1). The radial distribution of tangential velocities (see Fig. 3 of Kersalé et al. 2013 and accompanying text) was also used to estimate the region of the eddy in solid-body rotation, and hence its horizontal diameter. Tangential velocities linearly increased to average maximum values $V_{\max }$ of $\sim 0.35 \mathrm{~m} \mathrm{~s}^{-1}$, at radial distances $R_{\max }$ between 9 and 15 
$\mathrm{km}$. Thus, the in situ estimate of eddy dimensions is very close to that from the model (mean radius of $14.3 \mathrm{~km}$ based on the WATERS wavelet analysis described in Section 2.1). Analogously, the eddy vertical extents from model and observations were also very close, being $37 \mathrm{~m}$ and $35 \mathrm{~m}$, respectively. The local Rossby number $\mathrm{R}_{o}$ and the Rossby radius of deformation $\mathrm{R}_{d}$ were also estimated at 0.26 and $5.9 \mathrm{~km}$, respectively. Since $\mathrm{R}_{\max }>\mathrm{R}_{d}$, this eddy was classified as a mesoscale structure. Nonetheless the local Rossby number was not small, so its dynamics could not be approximated by quasi-geostrophic theory.

Coastal dynamics was quite different for the Latex10 campaign in September 2010, during which no anticyclonic structure was present. AVHRR pseudoSST imagery showed that the circulation in the western part of the GoL was characterized by the development of a strong thermal front (Figure 7 f). The combined analysis of ship-based and Lagrangian observations revealed that the front was associated with an intense flow $10 \mathrm{~km}$ wide and roughly parallel to the coast, through which waters from the continental shelf left the GoL towards the Catalan Basin (Nencioli et al. 2011). The front was formed due to the convergence, and the resulting stirring, of warmer open Northwestern Mediterranean waters, with colder waters on the continental shelf (respectively, $\mathrm{O}$ and $\mathrm{C}$ waters in Nencioli et al. 2013, 2016). Analysis of wind data and drifter trajectories indicated that the movement of the former was mainly driven by the $\mathrm{NC}$ dynamics along the continental slope, whereas the latter were advected southward out of the GoL due to Ekman flow following strong NW wind events.

Therefore, the front formation was mainly driven by the stirring induced by the interaction between wind-induced and large-scale circulation (Nencioli et al. 2016). Analysis of temperature, salinity and density data from crossfront transects showed that the front was mostly density-compensated (Nencioli et al., 2013). Temperature (salinity) gradients could reach up to $2^{\circ} \mathrm{C}$ $(0.4 \mathrm{psu})$ over less than $4 \mathrm{~km}$ across the front. The distribution of the vorticity Rossby number across the front showed predominant values smaller than $\mathcal{O}(1)$, with occasional maxima around $\mathcal{O}(1)$ (Nencioli et al., 2016, SI, Fig. 6). This indicated that the Latex10 front was mainly associated with geostrophic (i.e. mesoscale) dynamics. Therefore, although a surface intensified geostrophic flow and stronger vertical velocities may have occasionally occurred where the horizontal density gradient and relative vertical vorticity were large, the role of the local frontal dynamics was not explored. The implicit assumption is that horizontal advection by the geostrophic and Ekman flows that induced the formation of the front had stronger impact on the front's dynamics and temporal evolution than secondary ageostrophic circulation (Nencioli et al. 2013, 2016). 
4 Design of field experiments to investigate coastal (sub)mesoscale 2 structures

3 A powerful approach to quantify complex and ephemeral physical coastal processes is to perform the study in a Lagrangian reference frame with an adaptive strategy. This allows for the deconvolution of advection versus dispersion processes. At the time of the submission of the LATEX project to funding agencies, Lagrangian strategies were not as commonly used as now. Together with Griffa et al. (2007), LATEX was a pioneer study in adopting this type of approach. The main three examples of adaptive Lagrangian sampling strategy used during LATEX are presented in the next subsections.

$11 \quad 4.1$ Eddy in situ tracking (Latex08 and Latex09 - $R / V$ Téthys II)

During Latex08 and Latex09, a methodology to identify, follow and in situ sample an eddy, was developed, tested and improved. Before the cruise, analysis of pseudo-SST and ocean color satellite imagery was used to identify the presence of mesoscale eddies. If an eddy was detected, its center and potential translation speed were estimated with these data. This information was compared to and integrated with the results from the numerical simulations described in Section 2.1. The results were used to define the position and orientation of the first radial section across the eddy center for the collection of in situ $\mathrm{ADCP}$ and $\mathrm{CTD}$ (or XBT in case of bad sea conditions) observations. The ADCP measurements collected by the ship hull-mounted ADCP were then used to identify the position of the eddy center after each ship transect based on the algorithm developed by Nencioli et al. (2008). In the case of Latex08, this was done post cruise. However, for Latex09, the data processing chain was optimized and the work was done on-board in near real-time. This way, the precision of the center position was greatly improved compared to that estimated qualitatively from satellite imagery. The sampling strategy of the rest of the campaign was adapted with respect to each new calculated eddy center position, with the deployment of SVP drifters at the center or the edge of the eddy and multiple transects crossing the center either orthogonally or in a "butterfly" trajectory (Fig. 6 and refer to Hu et al. (2011b); Kersalé et al. (2013) for details).

34.2 Direct LCS iterative sampling (Latex10 - R/V Téthys II)

34 In the absence of a marked mesoscale structure, instead of the planned tracking and tracer injection of an eddy, the strategy was adapted to a (sub)mesoscale process study. The complexity of features visible from satellite chlorophyll-a and pseudo-SST maps, model circulation outputs and glider data rendered this task particularly challenging. The process study included the direct real-time detection of LCSs. This was tested with a novel, iterative, in situ sampling 
1 strategy (Nencioli et al., 2011) which combined satellite altimetry data, shipbased ADCP measurements, and iterative Lagrangian drifter releases (Figure 7). Three arrays of drifters were released at intervals of a few days to obtain in situ estimates of the structures. The dispersion pattern of the first drifter array on September 12 confirmed the presence of the along-shelf LCSs associated with the NC identified from AVISO velocities (Figure $7 \mathrm{a}$ ). The deployment position and the spatial configuration of the second and third array were chosen on the basis of the outcome of the previous launches. In situ repelling (red) and attracting (blue) LCSs identified and tracked the migration of an hyperbolic point for a period of 12 days, indicating that Lagrangian diagnostics such as FTLE and FSLE can be successfully identified even in the complex and variable flows typical of coastal regions (Nencioli et al. 2011). Nevertheless, in situ-based LCSs (also confirmed by ADCP observations) showed an opposite circulation compared to the AVISO field over the continental shelf, confirming the limitation of traditional altimetry for reliable transport analysis in those regions (Nencioli et al. 2011). To develop methods to mitigate such altimetry limitations in coastal environment, LATEX float trajectories were used to test the use of region-specific optimal interpolation methods to generate maps of satellite-derived geostrophic current anomalies, ultimately providing better absolute geostrophic currents, once added to different mean circulation fields (Bouffard et al. 2014). Otherwise, during the cruise, the identification of the LCSs contributed to accurately identifying the location of the thermal front described in Section 3 and tracking its evolution, particularly when satellite imagery of pseudo-SST and ocean colour was not available due to cloud cover. This provided a decisive contribution for i) optimizing the sampling strategy for the collection of cross-front sections (Section 5.1), and ii) tracking the movement of water masses for the quantification of the cross-shelf fluxes associated with the front (Section 5.2.

\subsection{Tracer release (Latex00 - $R / V$ Téthys II, and Latex10 - $R / V$ Le Surô̂t)}

One of the goals of the Latex10 field experiment was to mark a dynamical mesoscale feature by releasing a passive tracer together with an array of Lagrangian buoys. The goal was to release the tracer in an initial patch as homogeneous as possible in the horizontal, and to study its turbulent mixing and dispersion while minimizing the contribution due to the advection. For that, it was necessary to continuously adjust the vessel route in order to remain as closely as possible in the Lagrangian reference frame moving with the investigated mesoscale structure. To accomplish this task, two of the four LATEX field campaigns were dedicated to the development of such a methodology. The first campaign, Latex00, aimed at demonstrating its feasibility; the last one, Latex10, performed a final test followed by the actual tracer experiment.

To perform the initial tracer release and subsequent mappings in a Lagrangian reference frame, the movement of the targeted water mass was tracked using a reference buoy as a proxy. Our approach consisted in solving a classical 
ballistic problem to obtain, in real-time and in a moving water mass, the direction and distance to the next turn point of a chosen geometric route (details in Doglioli et al. (2013)). Results from the two field experiments showed that accuracy and frequency of acquisition of both vessel and buoy positions are key aspects for the successful implementation of this methodology.

The observational experience and analytical tools developed within LATEX led to a successful Lagrangian tracer release during the Latex10 experiment. The area for the tracer dispersion experiment was selected combining the numerical model results with those from the near real-time analysis of FSLEs computed from satellite-altimetry derived currents (Nencioli et al., 2011). The tracer was released in a patch of dimensions roughly $25 \mathrm{~km}^{2} \times 25 \mathrm{~m}$, smaller than initially planned. After the release, the horizontal evolution of the tracer patch was monitored for 7 days during a series of 4 successive horizontal mappings done at $7 \mathrm{~m}$ depth, the depth of the tracer release (Kersalé et al., 2015).

The software developed for the Lagrangian tracer experiment is included in the LATEXtools software suite. Our methodology presents some important technological improvements with respect to previous tracer studies related to both the positioning of the central buoy and the communication system with it. The software is also equipped with a series of graphical and user-friendly accessories. LATEXtools is written in Matlab, and can be freely downloaded from www.mio.univ-amu.fr/LATEX

\section{Horizontal mixing and cross-shelf exchanges}

23 The tracer experiment from the $R / V$ Le Suroit during Latex10 allowed a first estimate of lateral diffusivity at (sub)mesoscale (Kersalé et al., 2015). A second estimate was obtained by combining the strain rate from the drifter release, with the temperature and salinity gradients from thermosalinograph observations collected aboard the $R / V$ Téthys $I I$ (Nencioli et al. 2013). Finally, the combined analysis of in situ measurements and numerical modeling results provided a quantification of surface cross-shelf fluxes in the western GoL, the ultimate goal of the LATEX project.

5.1 Lateral diffusivities from tracer release and cross-front transects

The dispersion of the patch of the passive tracer $S F_{6}$, released in the adaptive Lagrangian framework described in 4.3 , was used to obtain a first estimate of the lateral diffusivity in the coastal waters of the western part of the GoL. After having quantified atmospheric loss of the $S F_{6}$, the temporal evolution of the patch was fit with a diffusion-strain model to obtain estimates of the strain rate $\gamma=2.510^{-6} \mathrm{~s}^{-1}$ and of the lateral diffusivity coefficient $K_{h}=23.2 \mathrm{~m}^{2} \mathrm{~s}^{-1}$ (Fig. 8 top panel). To test the robustness of this estimate, a steady state model was also applied, showing $K_{h}$ values similar to the diffusion-strain model after a period of adjustment between 2 and 4.5 days. This implied that, after such 
period, the computation of $K_{h}$ became independent from the further straining of the patch. The thermal front present southeast of the initial patch clearly affected the dynamics within the region and thus the temporal evolution of the patch (see Kersalé et al. (2015) for additional details). Nonetheless the results were consistent with previous studies in the open ocean (refer to the end of the section for more details) and demonstrated the success and feasibility of these methods also under small-scale, rapidly-evolving dynamics typical of coastal environments. However, one should note that this type of approach is still a challenge. Among the difficulties encountered, some are worth mentioning: issues related to fitting a Gaussian dispersion model to a patch which, under the stretching induced by the front, does not exhibit a Gaussian shape; technical limitations, making it difficult to sample the whole fast-dispersing patch, due both to vessel speed and $S F_{6}$ analysis time, affecting the sampling frequency. One of the objectives of the tracer experiment was also to determine the vertical diffusivity $\mathrm{Kz}$, and to compare it with the values derived from turbulence profiles acquired with the SCAMP. But lack of resolution in the vertical sampling of the tracer made the imprecision of the method too large to obtain reliable estimates. Nonetheless, turbulence profiles, acquired with the SCAMP, have been used in a numerical study investigating the impact of turbulence closure schemes and boundary conditions on the evaluation of $\mathrm{Kz}$ and energy dissipation rate (Costa et al. 2016).

A second estimate of in situ lateral diffusivity coefficients at the (sub)mesoscale was based on an analogous hypothesis of balance between mesoscale straining and small scale mixing adopted for passive tracer experiments. However, instead of using the shape of the tracer patch, the analysis was based this time on the width of the thermohaline front (Nencioli et al., 2013). The assumption at the base of this second approach is that, once a near steady-state is reached, the shape of the front will result from the balance between its straininduced steepening and its diffusion-induced relaxation. Such an approach has already been applied by Flament et al. (1985), who quantified eddy diffusivity by combining the cross-front width derived from temperature variations observed along a single ship-based cross-front section, with an approximate estimate of the cross-front convergence rate derived from successive satellite imagery of surface temperature. During Latex10, a series of front widths were obtained, instead, by fitting multiple high-resolution temperature and salinity cross-front sections with an analytical model for the cross-front profile at the equilibrium. The front widths were then combined to the local strain rate estimates derived from the dispersion of two arrays of Lagrangian drifters to retrieve horizontal eddy diffusivities (see Nencioli et al. (2013) for details on the equations). Latex10 adaptive sampling allowed the collection of 19 crossfront transects within a span of 9 days, from which a total of 76 estimates of lateral diffusivity $K_{h}$ (19 SST transects, 19 SSS transects and 2 estimates of strain rate) were computed. Their distribution is log-normal with a broad peak at values below $2.5 \mathrm{~m}^{2} \mathrm{~s}^{-1}$, and by a relatively long tail of episodic occurrences at values above $7.5 \mathrm{~m}^{2} \mathrm{~s}^{-1}$ (Fig. 8, bottom panel). The distribution ranged 
from a lowest value of $0.06 \mathrm{~m}^{2} \mathrm{~s}^{-1}$ to a maximum value of $46.67 \mathrm{~m}^{2} \mathrm{~s}^{-1}$, with $70 \%$ of the values between 0.4 and $5 \mathrm{~m}^{2} \mathrm{~s}^{-1}$. The mean $K_{h}$ computed using all estimates available was $3.98 \mathrm{~m}^{2} \mathrm{~s}^{-1}$, with a standard deviation of 7.26 $\mathrm{m}^{2} \mathrm{~s}^{-1}$. Further details on $K_{h}$ statistics, including the impact of higher but less frequent estimates, can be found in (Nencioli et al., 2013). Despite some expected differences, the distribution of $K_{h}$ estimated from the SST profiles was characterized by a similar shape as the one from the SSS profiles (Fig. 8 bottom panel). Moreover it is noteworthy that, although being characterized by different ranges, SST and SSS gradients from the same section returned similar estimates of $K_{h}$. This was an important feature since it showed that the estimates of $K_{h}$ using this approach were primarily controlled by the front width and were, at the same time, relatively independent from the magnitude of the tracer variation across the front.

The mean values of $K_{h}$ obtained with the two methods corresponded, respectively, to spatial scales of the order of i) the width of the patch $(10 \mathrm{~km})$ or ii) the cross-front distance (here below $5 \mathrm{~km}$ ). As mentioned in the introduction, at scales on the order of $10 \mathrm{~km}$, lateral diffusivities had been found of the order of $10 \mathrm{~m}^{2} \mathrm{~s}^{-1}$ (Ledwell and Watson, 1991, Holtermann et al., 2012). These results are also in agreement with the estimates from the LatMix project in summer 2011, a year after Latex10. LatMix used different tracers (rhodamine and fluorescein) and mapping techniques (lidar) than LATEX. Isopycnal diffusivities were also calculated from drifter trajectories. The values obtained were of the order of $1 \mathrm{~m}^{2} \mathrm{~s}^{-1}$ at scales on the order of 1-5 km (Shcherbina et al. 2015).

\subsection{Surface cross-shelf fluxes}

During the LATEX project, two main dynamical situations were observed in the western part of the GoL:

1. the presence of an anticyclonic eddy, during which exchanges were investigated from a numerical model, backed-up by Latex09 observations;

2. the case of a frontal structure when no eddy was present; the exchanges were quantified from Latex10 observations.

When a mesoscale structure is present in the western part of the GoL, it can lose a portion of itself by a peeling mechanism either linked to the topography (Nof, 1999) or to the large scale forcing (for example, squeezing by the NC such as in Kersalé et al. (2013), previously described in section 3). These detached bits are generally transient structures, that can move relatively quickly out of the Gulf, contributing to the cross-shelf exchanges. In 2009, two Lagrangian floats, deployed in the LatexA2_09 eddy, rotated in it for, respectively, two and four and a half days (Fig. 9). The float that had stayed the longest in the eddy was then caught in the coastal northward jet. The other one left the eddy and moved southward performing anticyclonic rotations. These, although in the clockwise direction, were not due to inertial oscillations, since their period 
was about 39 hours (while the near-inertial oscillations (NIO) have a period of 17.5 hours). The numerical simulations provided the necessary information to explain such drifter trajectory. Fig. 9 shows the drifters trajectories superposed to modeled relative vorticity, suggesting that the southward moving drifter joined another eddy present in the Catalan basin. The position of the Catalan eddy is located in the model further east than suggested by the float rotations. Despite the use of hybrid sigma coordinates, the strong bathymetry gradients are probably responsible for this shift in modeled circulation features.Nevertheless, the numerical simulations confirmed the mass exchanges modulated by eddy activity between the GoL and the Catalan shelf. The mass of the transient structure represented a third of the initial LatexA2_09 eddy mass. The latter lost $\sim 40 \%$ of its mass during the separation. The mass (or volume) contribution to the Catalan eddy could not be assessed, the latter being cut by the model boundary. The volume of the transient structure is estimated to $12.1 \pm 0.1 \mathrm{~km}^{3}$. This flux leaving the GoL could occur several times during the life of an eddy.

When no mesoscale eddies are present, the outer edge of the western GoL is characterized by the thermal front observed during Latex10 (see Section 3). The analysis integrated the observations from multiple platforms in order to: i) identify the different water masses, their origins and track their movements; ii) remove the signal associated with NIO from instantaneous ADCP velocities; and hence iii) calculate accurate cross-shelf exchanges within the upper mixed layer associated with the front (Nencioli et al., 2016). Water masses were identified and tracked from successive satellite imagery and Lagrangian observations (see Section 2.3). The reconstructed in situ LCSs also provided a reference frame to quantify cross-shelf exchanges. Since the flow associated with the front was approximately nondivergent, the transport of a given water volume along the LCS tangle was conserved for different sections across the structures. Therefore, sections across the LCSs were used to compute crossshelf exchanges even if not collected along the GoL boundary (i.e. the continental slope). Finally, Lagrangian drifter trajectories were also used to quantify NIO. Strong NIO can have important impacts on current strengths and fluxes in the region (Millot and Crépon, 1981; Petrenko et al. 2005, 2008). Most of the Latex10 drifter trajectories exhibited several clockwise loops with period around $\sim 17.5$ hours, indicating the presence of NIO. The time-series of their zonal and meridional components evidenced large oscillations superimposed to a slowly varying mean. As expected, the two components were out of phase by $90^{\circ}$, with positive meridional components preceding positive zonal ones. Following Haza et al. (2008), the mean velocity components were retrieved by applying a moving average based on a Gaussian window with a full width at half maximum (FWHM) of 17.5 hours. The NIO components were then computed as the residuals, i.e. the difference between original and averaged values. These NIO components were removed from the instantaneous ADCP observations from the cross-front sections used to compute the cross-shelf exchanges. Limits of integration along each section were defined based on thermosalino- 
graph observations which were used to identify the boundaries between the various outflowing and inflowing water masses.

The results indicated an average outflow of $0.074 \pm 0.012 \mathrm{~Sv}$ and an inflow of $0.021 \pm 0.006 \mathrm{~Sv}$ (Fig. 10). Integrated over the two-week lifetime of the front, such outflow would induce a total export of $\sim 90 \pm 14 \mathrm{~km}^{3}$ of water. Thus, 3 to 4 of such events would be sufficient to completely renew the surface waters of the GoL. The total water import amounted to only $\sim 25 \pm 7 \mathrm{~km}^{3}$, less than a third of the outflow, hence suggesting larger inflows at depth or in the eastern part of the gulf to maintain the GoL volume balance. These in situ estimates represent a key term of comparison for the further development of numerical model- and satellite-based studies of cross-shelf exchanges associated with this type of processes. These cross-shelf exchanges can have impacts on biogeochemistry and ecology, as they can regulate the fluxes of carbon (Bauer and Druffel 1998: Gattuso et al. 1998) and nutrients (Grantham et al., 2004), as well as the dispersion of fish-larvae (Roughan et al., 2006) and pollutants (Gustafsson et al. 1998)

\section{Conclusion}

The results of the physics component of the LATEX project have addressed the three main questions raised in Section 1

1) Mesoscale dynamics in the western GoL includes coastal mesoscale eddies or strong fronts. The eddies are elliptic, baroclinic and anticyclonic. They are generated either by the combined effect of strong wind and stratification or by boundary current meanders ( $\mathrm{Hu}$ et al. $2009,2011 \mathrm{~b}$ a Kersalé et al., 2013). The observed strong thermal (and saline) front was density-compensated (Nencioli et al. 2013). The front generation was mainly driven by the stirring induced by the interaction between wind-forced and large-scale circulation.

2) Field experiments were designed to investigate coastal (sub)mesoscale structures. Throughout a series of successive oceanographic cruises, LATEX developed and optimized a methodology for an adaptive Lagrangian sampling. Such adaptive approach was successfully applied to detect coastal eddies $(\mathrm{Hu}$ et al., 2011b; Kersalé et al. 2013), to identify Lagrangian Coherent Structures (Nencioli et al. 2011), and used for the initial release of a passive tracer as homogeneously as possible in a Lagrangian framework (Doglioli et al., 2013).

3) Horizontal mixing and cross-shelf exchanges were quantified. Lateral diffusivity coefficients, calculated using different approaches, are in the range classically encountered for their associated scales (Kersalé et al., 2015, Nencioli et al. 2013). To calculate $K_{h}$, the project included both a more traditional passive tracer experiment, as well as a novel technique based on the combined analysis of strain rate and thermohaline gradients. The strain rate was obtained from the analysis of the Lyapunov exponents derived from the La- 
1 grangian floats (Nencioli et al. 2013).

2 Cross-shelf exchanges are strongly influenced by the dynamical conditions at the shelf edge. In the western GoL, these can be characterized by the presence of either mesoscale eddies or strong thermohaline fronts. Eddies can trap waters in their core ( $\mathrm{Hu}$ et al. 2011a) but can also get eroded by the slope current, losing non negligible percentage of their mass (Kersalé et al. 2013) all the way to potentially disappearing in the process. Fronts can act like corridors favoring strong cross-shelf inter-regional exchanges (Nencioli et al., 2016).

This paper has summarized the (sub)mesoscale dynamics studied during LATEX. Since all LATEX field experiments occurred in late summer, the focus has been mainly on stratified conditions. A schematic of the main surface circulation processes that can occur in the western GoL can be found in Fig. 11 This schematic of the surface layer exhibits four main dynamical conditions: a) retention of water by an eddy; b) peeling of an eddy into a transient structure and GoL-exiting cross-shelf flux at the southern edge; c) frontal structure and associated southward fluxes, as during Latex10; d) intrusion of a barotropic current on the shelf between the coast and the NC, during Northwestern wind. The first three cases were encountered during LATEX. The last case was studied numerically but with scarce in situ data collected before LATEX (Petrenko et al. 2008).

\section{Perspectives}

The arrival of the US-French wide-swath altimetry mission SWOT (Surface Water Ocean Topography, scheduled for 2021) will also be welcomed to improve the accuracy of the representation of coastal circulation structures and their temporal evolution. Thanks to its Synthetic Aperture Radar (SAR) interferometer, the SWOT satellite will provide precise altimetry measurements close to the coast. SWOT will also increase by an order of magnitude the resolution of $2 \mathrm{D}$ maps of sea surface height (SSH). As shown by LATEX modeling and in situ activities, coastal eddies and fronts have an important role in modulating cross-shelf exchanges, but due to their potentially small size they are often invisible in SSH images. Therefore, these structures are often detected only indirectly, either by in situ techniques - like drifter or glider experiments - or through remote sensing, by their signature in SST or Chl images. The availability of SWOT data will mark a new generation of experiments because it will relieve in situ operations from the task of identifying and following in time the fine-scale physical features. Once these features are accessible from remote sensing, in situ experiments will have the possibility of concentrating on the characterization of the fine-scale dynamics, using images of high-resolution altimetry for tracking submesoscale features, such as filaments and small eddies. This way, ship-time will be fully available for a proper characterization of the $3 \mathrm{D}$ dynamics occurring in between the mesoand the submeso-scale, addressing key uncertainties like the quantification of 
1 vertical fluxes of nutrient and carbon in frontal systems. In this regard, the Mediterranean sea is set to play a special role: due to its easy accessibility, small Rossby radius, energetic boundary currents, very low cloud coverage, and low tides, it is an ideal 'pocket ocean' where to combine high-resolution satellite observations and multi-platform in situ experiments. SWOT is expected to resolve features down to $15 \mathrm{~km}$ including near the coast. In turn, this information will hopefully improve the realism of circulation models, in particular their representation of biogeochemical processes.

This Review concentrated on the physics component of LATEX. So only a short summary is given here on what has been done concerning physicalbiogeochemical coupling and the perspectives that this work opens. The LATEX numerical study of the GoL circulation has allowed for the quantification of the impact of the anticyclonic eddy A1_01 on the ecosystem dynamics (Campbell et al. 2013). Additionally, the circulation model Symphonie was coupled with a biogeochemical model originating from the Eco3M modeling platform (Baklouti et al., 2006a b), and adapted as a pelagic plankton ecosystem model for the Northwestern Mediterranean basin by Auger et al. (2011). The eddy exhibited low productivity at its core and rising up of nutricline on its edges. However the functioning and consequences of the coastal eddy on nutrients and plankton distributions was complicated by potential interactions with topography, wind-induced upwelling along the coast and the nearby Northern Current. This coupled modeling is to be pursued to compare the numerical results with the in situ data collected during the Latex cruises (F. Diaz, LATEX PI for biogeochemistry; pers. comm.). More work needs to be done in order to estimate not only the impacts of LATEX eddies on biogeochemical budgets and cross-shelf transfers, but also to comprehend the coupling of physics and biogeochemistry at (sub)mesoscale in this zone.

The LATEX adaptive real-time Lagrangian strategy needs also to be accompanied with 3D in situ observations and fast, automated physical and biogeochemical sampling in order, among others, to explore surface semigeostrophic model (Badin, 2013) and to study processes associated with eddies, fronts and filaments (e.g. frontogenesis/frontolysis as in Hoskins (1982)), as well as coupled physical-biogeochemical processes at the submesoscale. This challenge was already highlighted in the open ocean (Lévy et al., 2012), and remains highly relevant in the coastal environment.

\section{${ }_{36}$ Availability of the LATEX and SPASSO codes}

The LATEXtools software (Doglioli et al. 2013) is available freely on the LATEX web site: www.mio.univ-amu.fr/LATEX To our knowledge, no other papers report detailed descriptions of the techniques and software adopted for Lagrangian tracer release and sampling strategy, although they are a key point for the success of in situ tracer experiments. We are nonetheless aware of the now available Google Earth interactive map of the LatMix project (http://dx.doi.org/10.1175/BAMS-D-14-00015.2). Since 2010, the LATEX La- 
1 grangian strategy has been further developed and successfully applied during several other ocean campaigns such as KEOPS2 in 2011 (Quéguiner, 2011. 3 d'Ovidio et al., 2015), STRASSE in 2012 (Reverdin et al., 2015) and, in ${ }_{4}$ 2015, OUTPACE (Moutin and Bonnet, 2015) and OSCAHR (Doglioli, 2015). 5 In the continuity of LATEXtools, SPASSO (Software Package for an Adap6 tive Satellite-based Sampling for Ocean campaigns, available at www.mio. 7 univ-amu.fr/SPASSO) retrieves and processes satellite data on land and then 8 transmits them on board. The analysis of the collected information (including 9 in situ data and available model predictions, in addition to the satellite data) is to done on land and allows to prepare daily bulletins with suggestions for optimal 1 ship routing and station positioning. These bulletins are then send on board, 12 as well as made available through dedicated web pages. SPASSO is planned to 13 be used for the cruises PEACETIME (2017, PIs: C. Guieu and K. Desboeufs), 14 SARGASSES (2017, PIs: L. Berline and T. Thibaut) and BIOSWOT (2018, 5 PI: F. d'Ovidio).

Acknowledgements The LATEX project was supported by the programs LEFE/IDAO and LEFE/CYBER of the INSU-Institut National des Sciences de l'Univers and by the Region PACA-Provence Alpes Côte d'Azur. The PIs of the project were A. Petrenko for the physics component and F. Diaz for the biogeochemical component. The chief scientists were A. Petrenko on board the $R / V$ Téthys $I I$ for Latex00, Latex07, Latex08, Latex09 and Latex10 and B. Quéguiner on board the $R / V$ Le Suroît for Latex10. The scientist in charge of the tracer release was S. Blain. M. Kersalé and Z.Y. Hu were financed by MENRT Ph.D. grants. F.Nencioli acknowledges support from the FP7 Marie Curie Actions of the European Commission, via the Intra-European Fellowship (FP7-PEOPLE-IEF-2011), project "Lyapunov Analysis in the COaSTal Environment" (LACOSTE-299834). We thank I. Dekeyser for his support and useful discussions. We have appreciated that Claude Estournel and Patrick Marsaleix provided us the initial Symphonie code and helped us along our configuration development. We acknowledge the MFSTEP program for OGCM outputs. Meteorological and AVHRR data were supplied by Météo-France. The DT-INSU is thanked for the treatment of the thermosalinograph data. The altimeter products were produced by Ssalto/Duacs and distributed by Aviso with support from CNES, that also financed the post-doc fellowship of Jérome Bouffard. The MODIS Aqua data were supplied by the Distributed Active Archive Center at NASA Goddard Space Flight Center and made possible by the MODIS Project. We thank the crews and technicians of the $R / V$ Le Surot $t$ and the $R / V$ Téthys $I I$, the DT-INSU and all the LATEX collaborators for their assistance at sea or during the project. A special thanks goes to, in alphabetical order: Anne Desnues, Jean-Luc Fuda, Nicolas Grima, Thierry Labasque, Deny Malengros, Peggy Rimmelin, Gilles Rougier and Anna Roumyantseva, for their work on the data collection and Lagrangian strategy, as well as Emmanuel Bosc for some chlorophyll-a satellite products. 


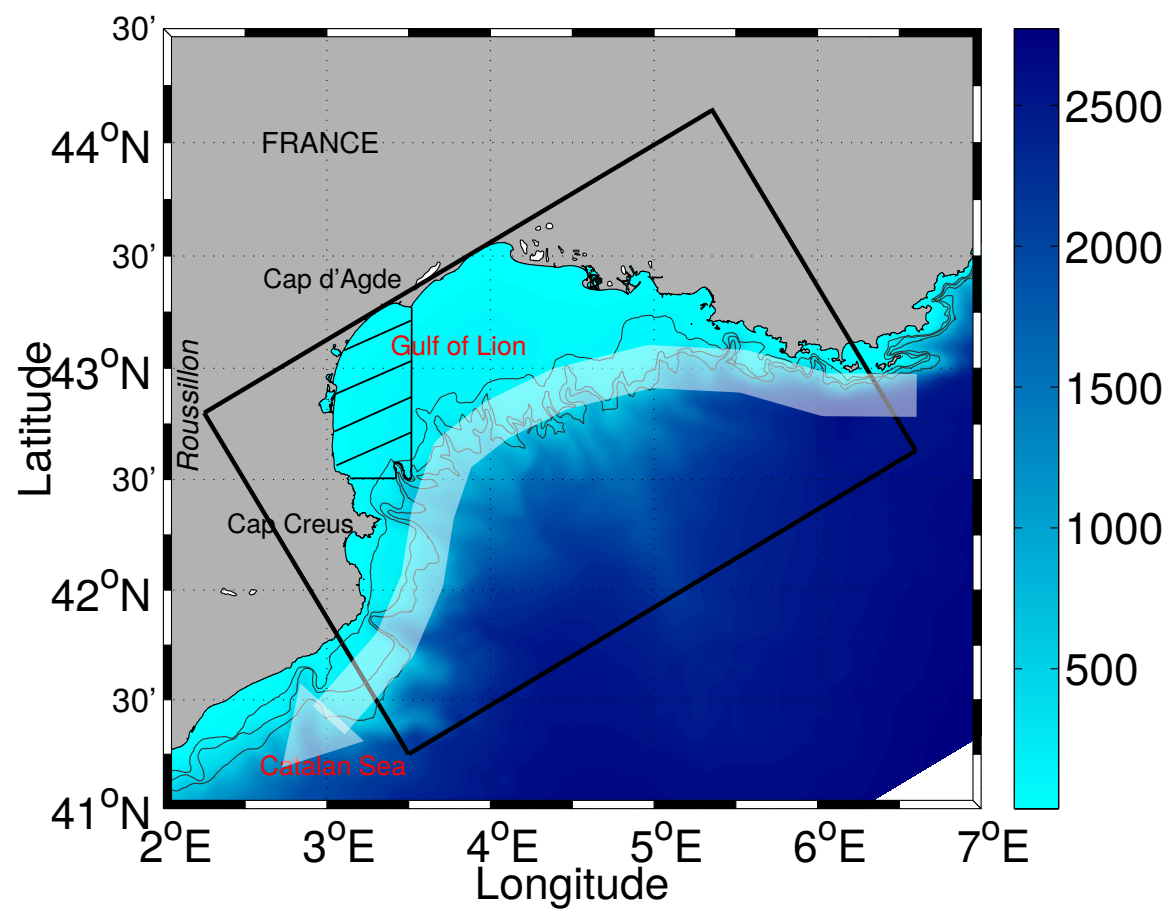

Fig. 1 Bathymetry of the Gulf of Lion. The rectangle represents the $1 \mathrm{~km}$ resolution model domain. Shaded color represents the bathymetry [m]. Isobaths at 100, 200 and $500 \mathrm{~m}$ are plotted with thin lines. The white arrow shows the mean position of the Northern Current (NC). The hatched area indicates the zone where the absolute value of potential energy anomaly $\phi$ is calculated 

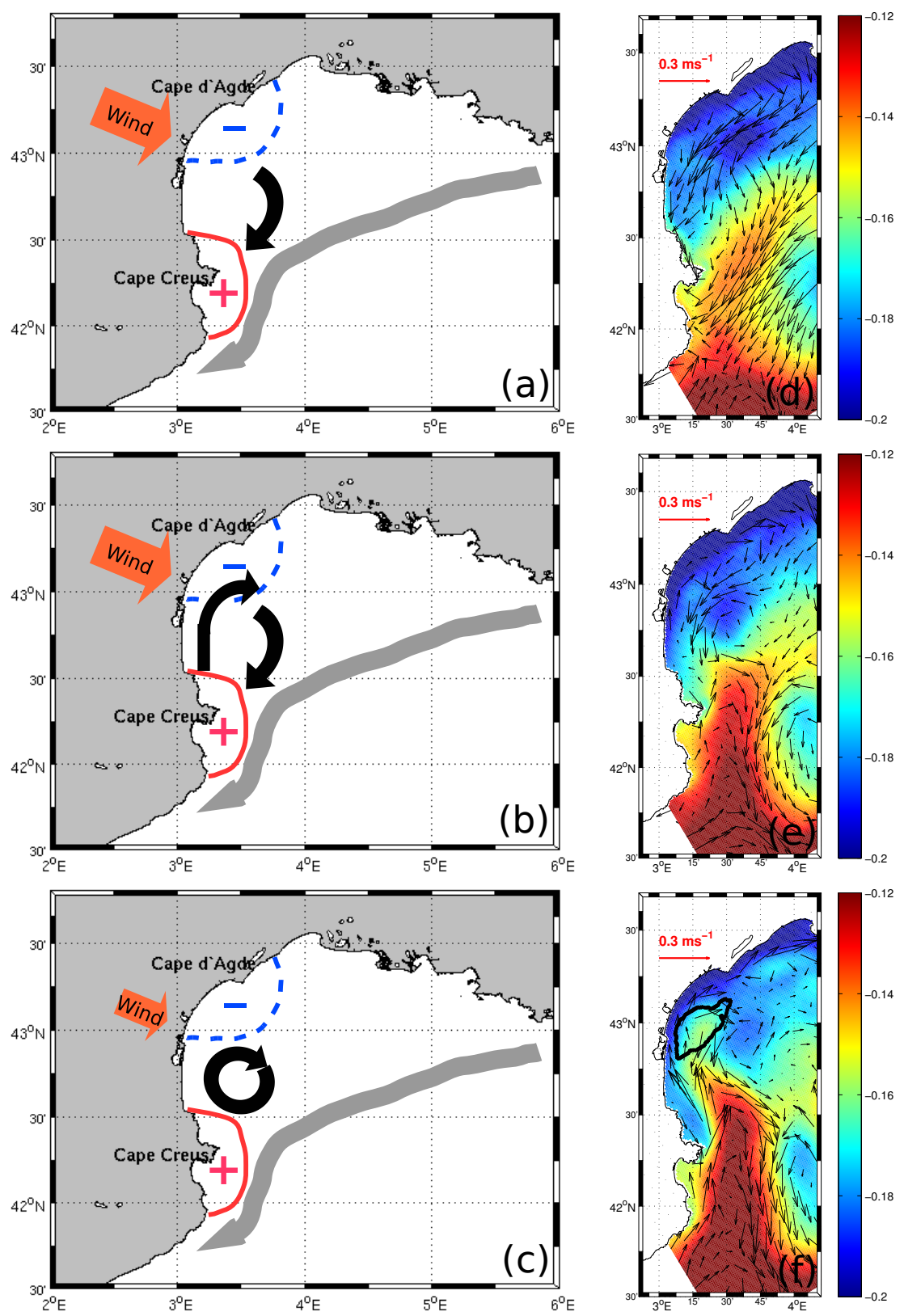

Fig. 2 Schematic generation of an anticyclonic eddy (from the 8-year numerical study of (Hu et al. 2011b)). The three main phases of the eddy generation process are represented: a) upwelling and Ekman flow, b) generation of a northward coastal jet, c) eddy generation. Eddy-related currents are represented by black arrows; upwelling area, corresponding to a negative Sea Level Anomaly (SLA), designated by the blue dashes around the minus sign; positive SLA area around Cape Creus designated by the red area around the positive sign; wind represented by the orange arrow; the NC by the grey arrow along the continental shelf. As an example, corresponding modeled sea surface height and velocity field at $5 \mathrm{~m}$ depth on d) July 02, 2005; e) July 07, 2005; and f) July 10, 2005 

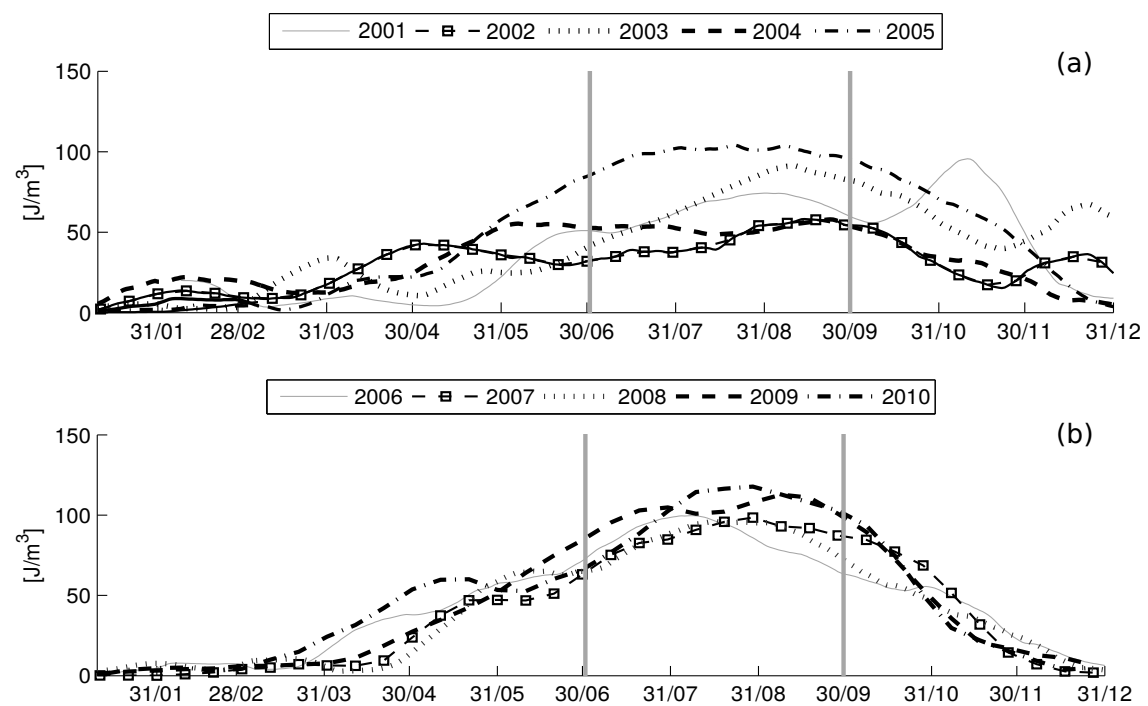

Fig. 3 Time series of 30 day moving averaged potential energy anomaly $\left[\mathrm{Jm}^{-3}\right]$ over the western part of the GoL for the upper $100 \mathrm{~m}$ depth for the years a) 2001 to 2005 and b) 2006 to 2010 

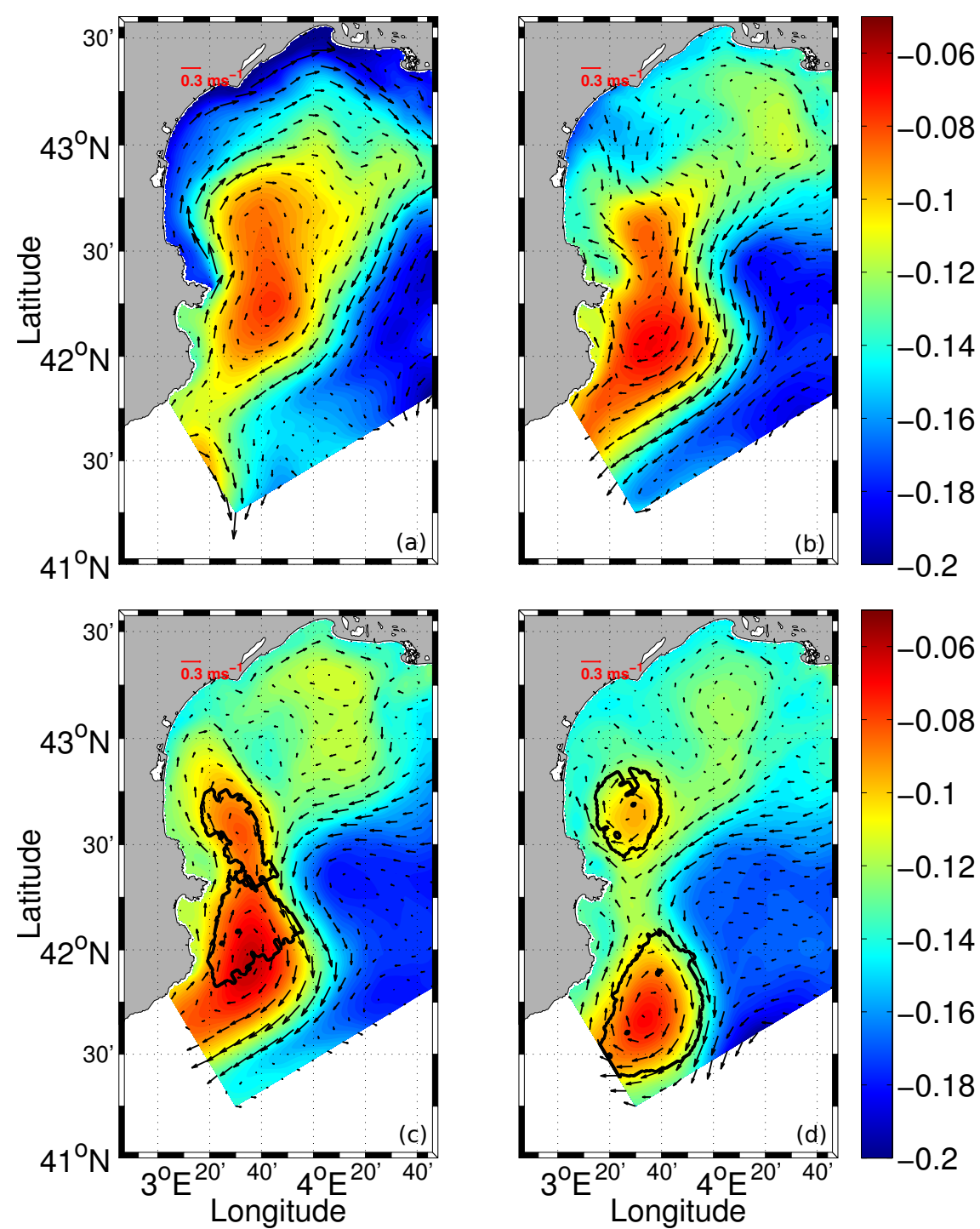

Fig. 4 Temporal sequence of formation of the eddy, sea surface height $[\mathrm{m}]$ and velocity field at $5 \mathrm{~m}$ depth $\left[\mathrm{ms}^{-1}\right]$, in four steps: July 20, Aug. 8, Aug. 16, and Aug.27, 2009 (adapted from Kersalé et al. (2013), with permission) 
Presence of eddies (>15 days)

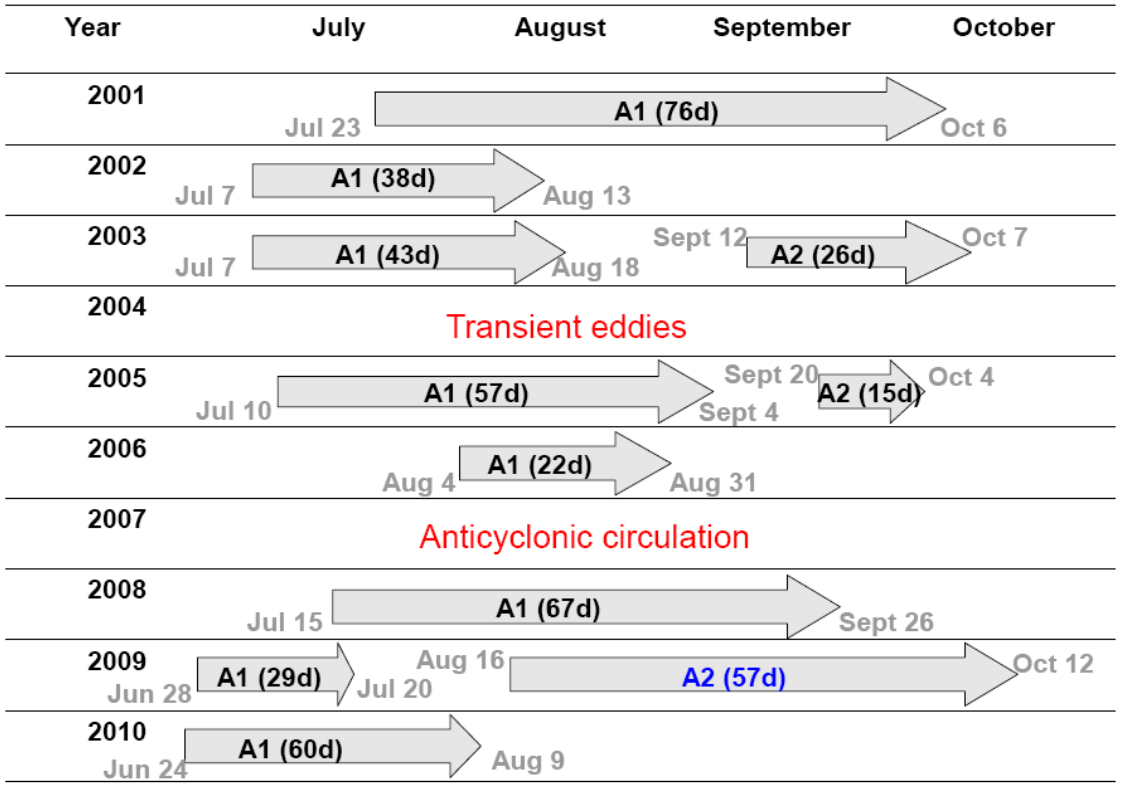

Fig. 5 Gantt table of the long-life modeled eddies from 2001 to 2010. The grey arrows indicate the duration of the first A1 or second A2 eddies, with the corresponding number of days in parenthesis. When this is written in black, the eddy has been generated with the first generation process ( $\mathrm{Hu}$ et al. 2011b). When in blue, it has been generated by the second generation process (Kersalé et al. 2013). The dates of birth and death of each eddy are also indicated 

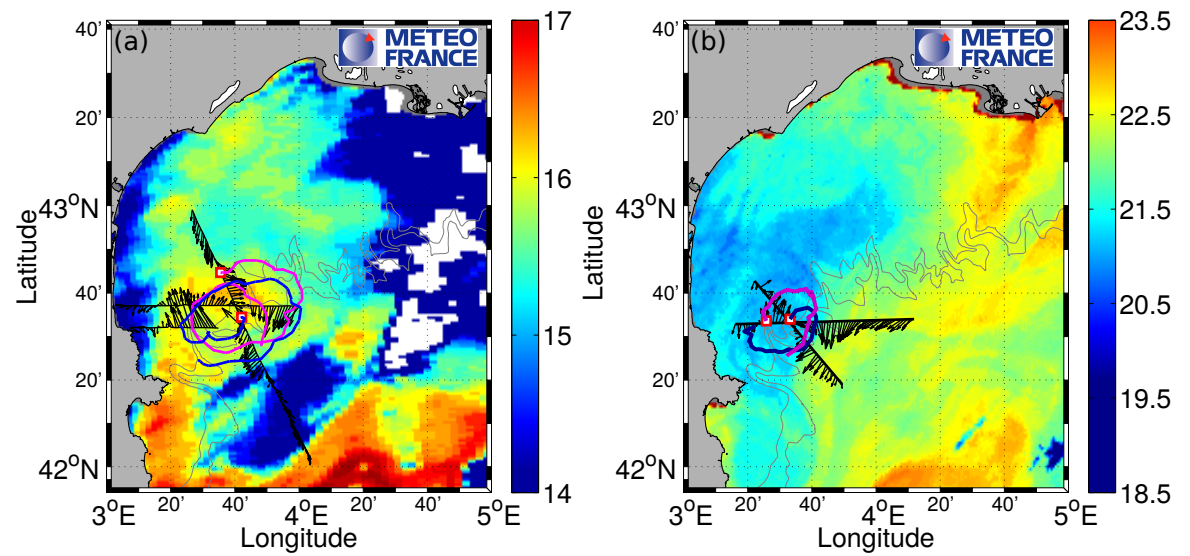

Fig. 6 Eddies studied a) during Latex08, b) during Latex09. ADCP transects, with horizontal currents at $15 \mathrm{~m}$ depth in black. SVP drifter trajectories are shown in blue and purple during a) 6 days, b) 3 days following their release at the location indicated with a red square. Pseudo-SST images on a) Sept. 02, 2008 and b) Aug. 28, 2009. 


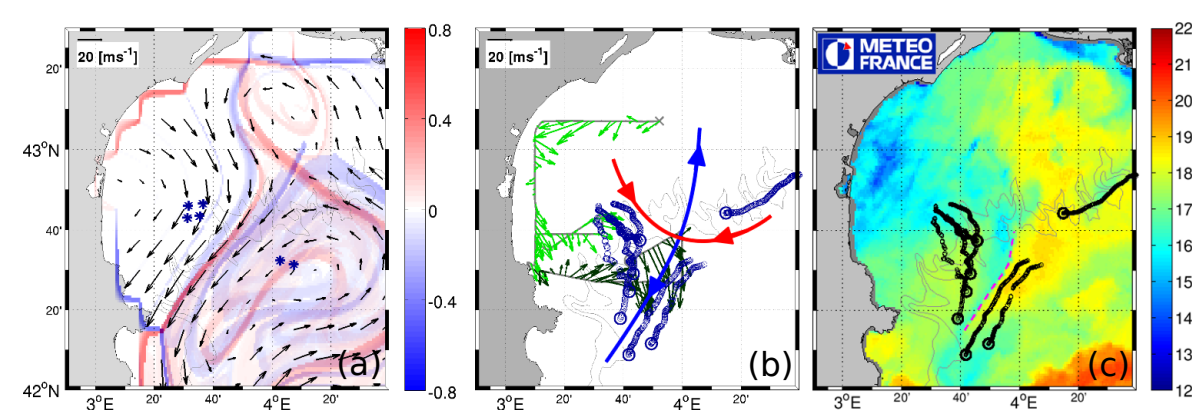

Fig. 7 a) Lagrangian coherent structures, FSLE in $\left[\mathrm{s}^{-1}\right]$ derived from AVISO geostrophic velocities on 14 September 2010 and release position of the Lyap01 cluster of Lagrangian drifters. In blue are the attracting LCS (backward FSLE) and in red the repelling ones (forward FSLE). b) ADCP currents, 3-day drifter trajectories and position of the Lagrangian coherent structures reconstructed from in situ measurements. c) image of pseudo-SST for Sept. 14, 2010 and 3-day drifter trajectories. The position of the front focus of the Latex10 field experiment is marked by the magenta dashed line. (adapted from Nencioli et al. (2011. 2016) with permission) 

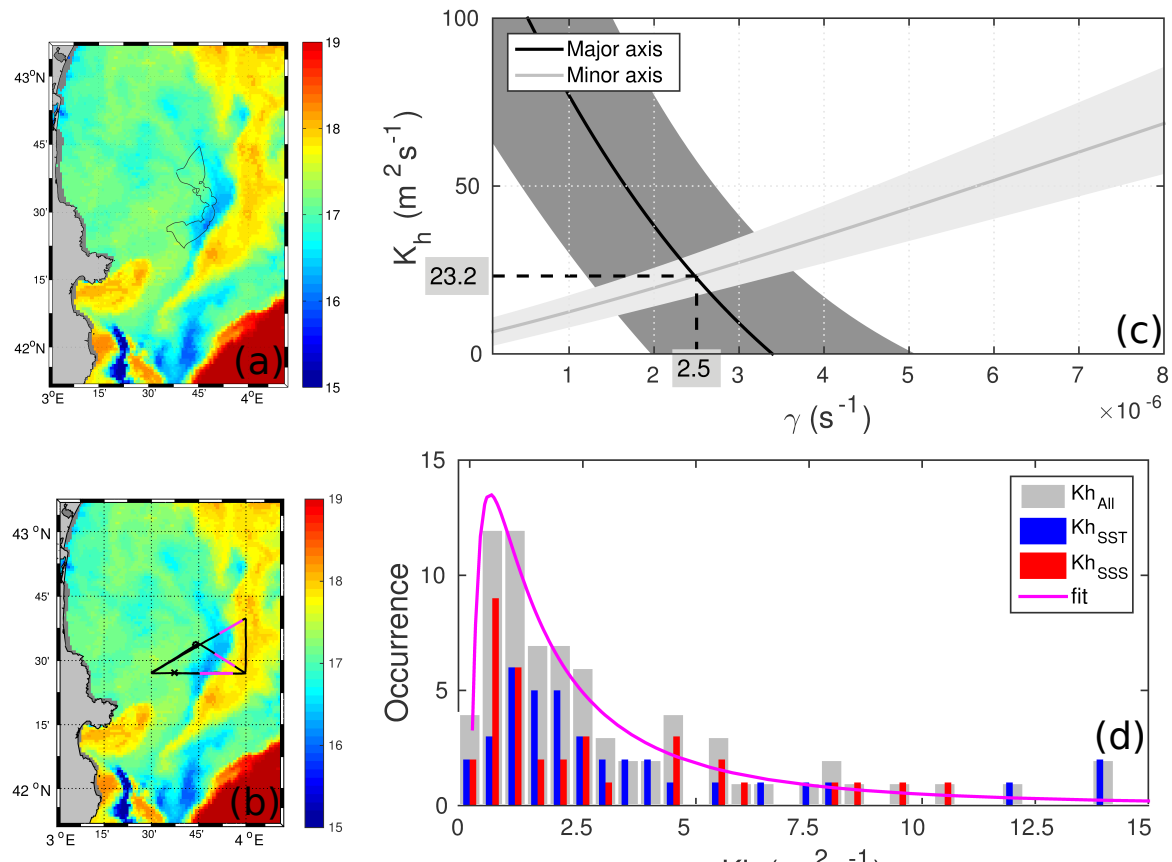

Fig. 8 Spatial scales and diffusivity coefficients. a) Pseudo-SST map on Sept. 15, 2010 with the contour of the 3rd $S F_{6}$ mapping; b) Same pseudo-SST map with examples of cross-front transects, the front SST gradient in red; c) The point of intersection of the two curves (major and minor axes, see Kersalé et al. (2015) for details) indicates the best estimates of $\gamma\left[\mathrm{s}^{-1}\right]$ and $K_{h}\left[\mathrm{~m}^{2} \mathrm{~s}^{-1}\right]$. The shaded areas represent the uncertainties; d) Frequency histogram of the horizontal eddy diffusion coefficients derived by Nencioli et al. (2013). In blue is the distribution of the $K_{H}$ estimated from the SST profiles only; in red the distribution of the $K_{H}$ from the SSS profiles only; and in grey the total distribution of the two combined together 


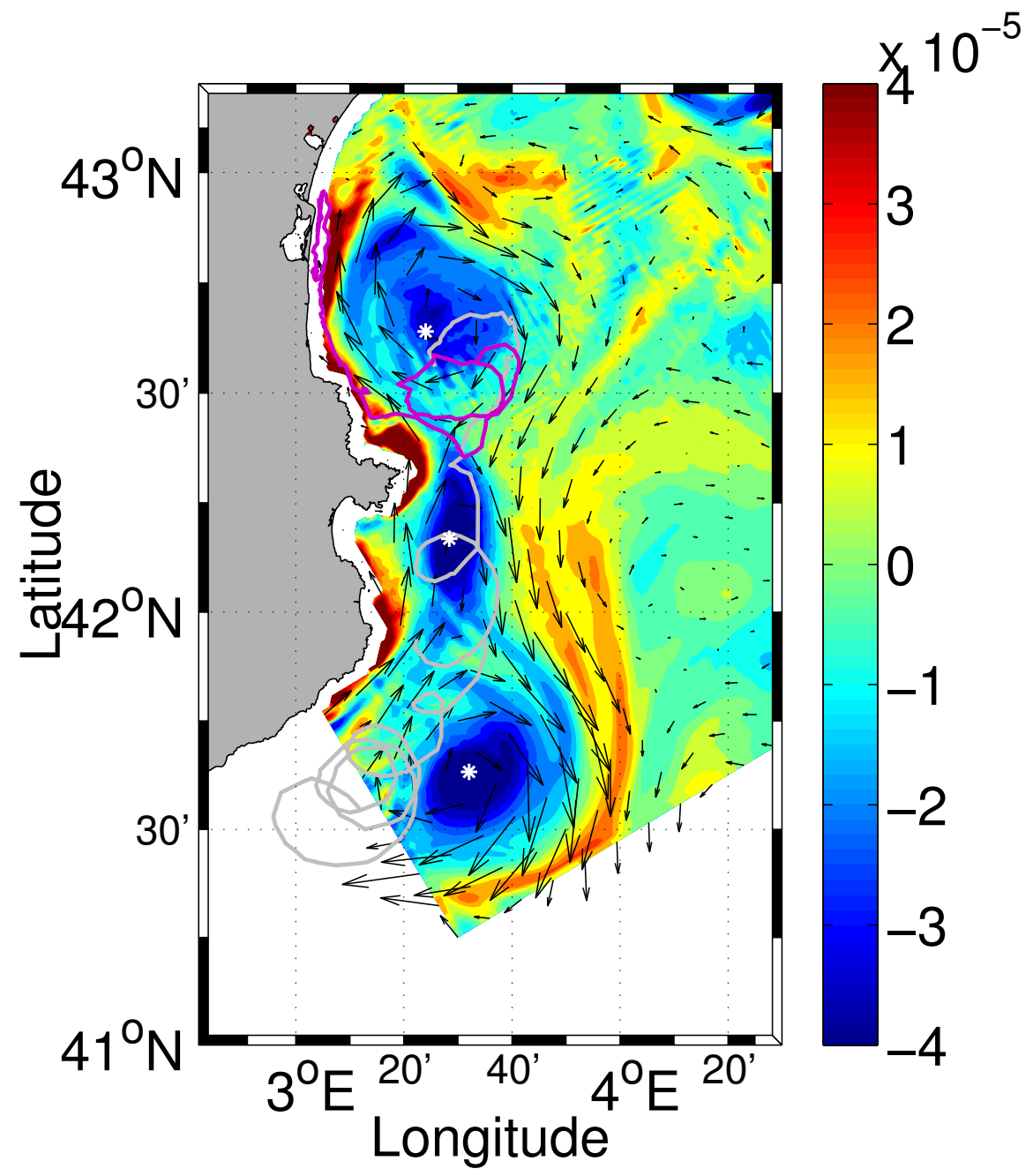

Fig. 9 Transient structure detaching from LatexA2_09. Modeled relative vorticity $\left[\mathrm{s}^{-1}\right]$, velocity field at $20 \mathrm{~m}$ depth on Sept. 3, 2009 (arrows) and drifter trajectories (grey and purple) from Aug. 26 to Sept. 11, 2009. The white stars represent each structure center 


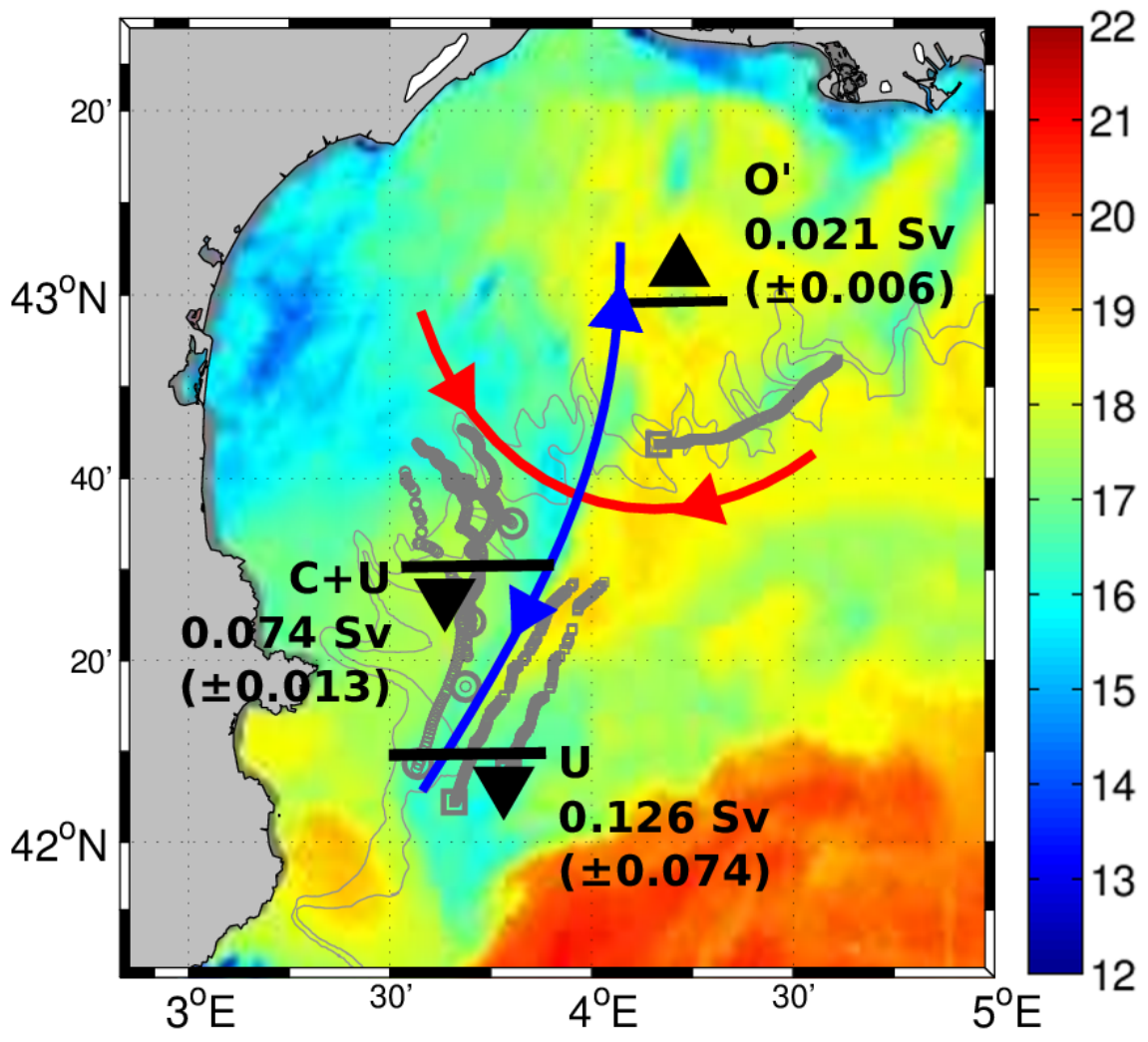

Fig. 10 Schematics of the average cross-shelf fluxes associated with the front from Latex10, superimposed on pseudo-SST, buoy trajectories (grey) and in situ LCSs (red and blue). Locations of outflow and inflow of the U (upwelled), C (coastal) and O' (modified open, see Nencioli et al. (2016) for details) waters are indicated relative to the Lyap01 LCS, as no cloud-free pseudo-SST images are available afterwards. (adapted from Nencioli et al. (2016) with permission) 


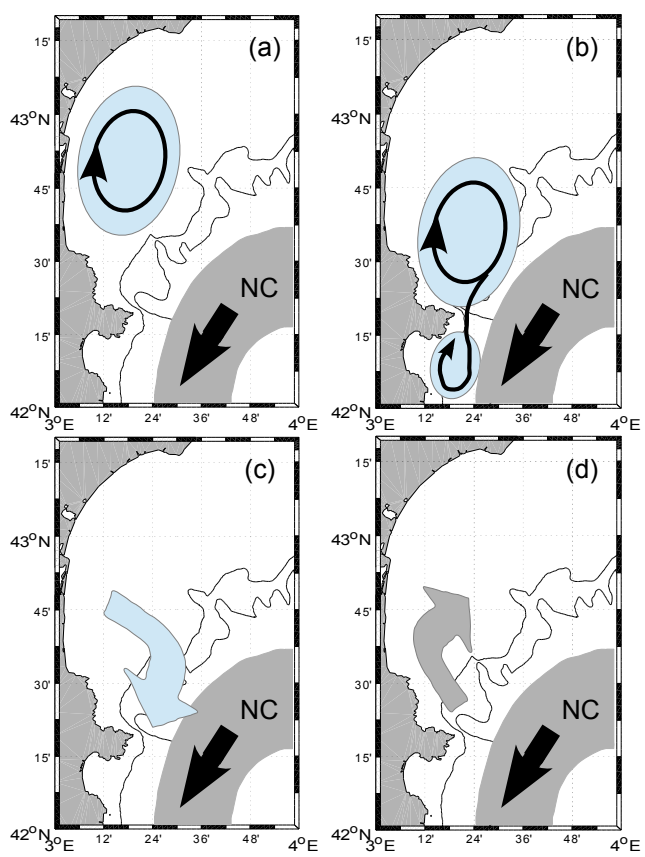

Fig. 11 Schematic of 4 main circulation patterns in the western GoL; a) water eddy retention; b) transient feature leaking from eddy; c) cross-shelf flux exiting the GoL; d) coastal jet entering the GoL. Blue (grey) areas indicate the preferential zones of baroclinic (barotropic) circulation features 


\section{References}

Abraham, E., Law, C., Boyd, P., Lavender, S., Maldonado, M., and Bowie, A. (2000). Importance of stirring in the development of an iron-fertilized phytoplankton bloom. Nature, 407:727-730.

Allou, A., Forget, P., and Devenon, J. L. (2010). Submesoscale vortex strucures at the entrance of the Gulf of Lions in the Northwestern Mediterranean Sea. Cont. Shelf Res., 30:724-732.

Auger, P. A., Diaz, F., Ulses, C., Estournel, C., Neveux, J., Joux, F., Pujo-Pay, M., and Naudin, J. J. (2011). Functioning of the planktonic ecosystem of the Rhone River plume (NW Mediterranean) during spring and its impact on the carbon export: a field data and 3-D modelling combined approach. Biogeosciences, 24(6):9039-9116.

Aurell, E., Boffetta, G., Crisanti, A., Paladin, G., and Vulpiani, A. (1997). Predictability in the large: an extension of the concept of Lyapunov exponent. J. Phys. A, 30(1):1.

Badin, G. (2013). Surface semi-geostrophic dynamics in the ocean. Geophys. Astrophys. Fluid Dynam., 107(5):526-540.

Baklouti, M., Diaz, F., Pinazo, C., Faure, V., and Quéguiner, B. (2006a). Investigation of mechanistic formulations depicting phytoplankton dynamics for models of marine pelagic ecosystems and description of a new model. Prog. Oceanogr., 71(1):1-33.

Baklouti, M., Faure, V., Pawlowski, L., and Sciandra, A. (2006b). Investigation and sensitivity analysis of a mechanistic phytoplankton model implemented in a new modular numerical tool (eco3m) dedicated to biogeochemical modelling. Prog. Oceanogr., 71(1):34-58.

Barrier, N., Petrenko, A. A., and Ourmières, Y. (2016). Strong intrusions of the Northern Mediterranean Current on the eastern Gulf of Lion: insights from in-situ observations and high resolution numerical modelling. Ocean Dynam., 66(3):313-327.

Bauer, J. E. and Druffel, E. R. M. (1998). Ocean margins as a significant source of organic matter to the deep open ocean. Nature, 392:482-485.

Beron Vera, F. J., Olascoaga, M. J., and Goni, G. J. (2008). Oceanic mesoscale eddies as revealed by Lagrangian coherent structures. Geophys. Res. Lett., $35(12)$.

Biscaye, P. E. (1994). Shelf edge exchange processes in the southern middle atlantic bight: Seep-ii. Deep Sea Res. I, 41(2-3):229-230.

Bosse, A., Testor, P., Houpert, L., Damien, P., Prieur, L., Hayes, D., Taillandier, V., Durrieu de Madron, X., d'Ortenzio, F., Coppola, L., Karstensen, J., and Mortier, L. (2016). Scales and dynamics of submesoscale coherent vortices formed by deep convection in the northwestern mediterranean sea. J. Geophys. Res., 121(10):7716-7742.

Bouffard, J., Nencioli, F., Escudier, R., Doglioli, A. M., Petrenko, A. A., Pascual, A., Poulain, P. M., and Elhmaidi, D. (2014). Lagrangian analysis of satellite-derived currents: Application to the North Western Mediterranean coastal dynamics. Adv. Space Res., 53(5):788-801. 
Bouffard, J., Vignudelli, S., Herrmann, M., Lyard, F., Marsaleix, P., Ménard, Y., and Cipollini, P. (2008). Comparison of ocean dynamics with a regional circulation model and improved altimetry in the North-western Mediterranean. In Terr. Atmos. Ocean. Sci., volume 19, pages 117-133.

Brink, K. H. and Cowles, T. J. (1991). The Coastal Transition Zone program. J. Geophys. Res., 96(C8):14637-14647.

Broche, P., Devenon, J.-L., Forget, P., de Maistre, J.-C., Naudin, J.-J., and Cauwet, G. (1998). Experimental study of the Rhone plume. Part I: physics and dynamics. Oceanol. Acta, 21(6):725-738.

Burchard, H. and Burchard, R. (2008). A dynamic equation for the potential energy anomaly for analysing mixing and stratification in estuaries and coastal seas. Estuar. Coast. Shelf S., 77(4):679-687.

Burchard, H., Craig, P. D., Gemmrich, J. R., van Haren, H., Mathieu, P.-P., Meier, H. M., Smith, W. A. M. N., Prandke, H., Rippeth, T. P., Skyllingstad, E. D., et al. (2008). Observational and numerical modeling methods for quantifying coastal ocean turbulence and mixing. J. Phys. Oceanogr., 76(4):399-442.

Campbell, R., F., D., Hu, Z., Doglioli, A., Petrenko, A., and Dekeyser, I. (2013). Nutrients and plankton spatial distributions induced by a coastal eddy in the Gulf of Lion. Insights from a numerical model. Prog. Oceanogr., 109:47-69.

Canals, M., Puig, P., de Madron, X. D., Heussner, S., Palanques, A., and Fabres, J. (2006). Flushing submarine canyons. Nature, 444(7117):354-7.

Capet, X., McWilliams, J., Molemaker, M., and Shchepetkin, A. (2008a). Mesoscale to submesoscale transition in the California Current System. Part I: Flow structure, eddy flux, and observational tests. J. Phys. Oceanogr., $38(1): 29-43$.

Capet, X., McWilliams, J. C., Molemaker, M. J., and Shchepetkin, A. (2008b). Mesoscale to submesoscale transition in the California Current System. Part II: Frontal processes. J. Phys. Oceanogr., 38(1):44-64.

Costa, A., Doglioli, A., Marsaleix, P., and Petrenko, A. (2016). Comparison of in situ microstructure measurements to different turbulence closure schemes in a 3-D numerical ocean circulation model. Ocean Model., (submitted).

Cotté, C., d'Ovidio, F., Chaigneau, A., Lévy, M., Taupier Letage, I., Mate, B., and Guinet, C. (2011). Scale-dependent interactions of Mediterranean whales with marine dynamics. Limnol. Oceanogr., 106(20):219-232.

Crawford, W. R. (2002). Physical characteristics of Haida Eddies. Journal of Oceanography, 58(5):703-713.

Csanady, G. (1982). Circulation in the coastal ocean. D.Reidel Publishing Company, Kluwer Group, Dordrech, Holland.

Cushman-Roisin, B. (1994). Introduction to Geophysical Fluid Dynamics. Prentice Hall.

De Boer, G. J., Pietrzak, J. D., and Winterwerp, J. C. (2008). Using the potential energy anomaly equation to investigate tidal straining and advection of stratification in a region of freshwater influence. Ocean Model., 22:1-11. 
1 De Monte, S., D’Ovidio, F., Cotté, C., Lévy, M., Le Corre, M., and Weimerskirch (2012). Frigatebird behaviour at the ocean-atmosphere interface: integrating animal behaviour with multisatellite data. J. R. Soc. Interface.

Di Lorenzo, E., Foreman, M. G. G., and Crawford, W. R. (2005). Modelling the generation of Haida Eddies. Deep-Sea Res. II, 52:853-873.

Doglioli, A. (2015). OSCAHR cruise, RV Téthys II, http://dx.doi.org/10.17600/15008800.

Doglioli, A., Nencioli, F., Petrenko, A. A., Fuda, J.-L., Rougier, G., and Grima, N. (2013). A software package and hardware tools for in situ experiments in a Lagrangian reference frame). J. Atmos. Ocean. Tech., 30(8).

Doglioli, A. M., Blanke, B., Speich, S., and Lapeyre, G. (2007). Tracking coherent structures in a regional ocean model with wavelet analysis: application to Cape Basin Eddies. J. Geophys. Res., 112.

d'Ovidio, F., De Monte, S., Alvain, S., Dandonneau, Y., and Lévy, M. (2010). Fluid dynamical niches of phytoplankton types. Proc. Natl. Acad. Sci. U. S. A., 107(43):18366-18370.

d'Ovidio, F., Della Penna, A., Trull, T. W., Nencioli, F., Pujol, M.-I., Rio, M.H., Park, Y.-H., Cotté, C., Zhou, M., and Blain, S. (2015). The biogeochemical structuring role of horizontal stirring: Lagrangian perspectives on iron delivery downstream of the Kerguelen Plateau. Biogeosciences, 12(19):55675581.

d'Ovidio, F., Fernéndez, V., Hernández-García, E., and López, C. (2004). Mixing structures in the mediterranean sea from finite-size lyapunov exponents. Geophys. Res. Lett., 31:L17203.

Durrieu, de Madron, X., Houpert, L., Puig, P., Sanchez-Vidal, A., Testor, P., Bosse, A., Estournel, C., Somot, S., Bourrin, F., and Bouin, M. N. (2013). Interaction of dense shelf water cascading and open-sea convection in the northwestern mediterranean during winter 2012. Geophys. Res. Lett., 40(7):1379-1385.

Durrieu De, Madron, X., Zervakis, V., Theocharis, A., and Georgopoulos, D. (2005). Comments on "cascades of dense water around the world ocean". Prog. Oceanogr., 64(1):83-90.

Estournel, C., Durrieu de Madron, X., Marsaleix, P., Auclair, F., Julliand, C., and Vehil, R. (2003). Observation and modeling of the winter coastal oceanic circulation in the Gulf of Lion under wind conditions influenced by the continental orography (FETCH experiment). J. Geophys. Res., 108(C3).

Ferrari, R. (2011). A frontal challenge for climate models. Science, $332(6027): 316-7$.

Flament, P., Armi, L., and Washburn, L. (1985). The evolving structure of an upwelling filament. J. Geophys. Res., 90(C6):11765-11778.

Flexas, M. M., Durrieu de Madron, X., Garcia, M. A., Canals, M., and Arnau, P. (2002). Flow variability in the Gulf of Lions during the MATER HFF experiment (March-May 1997). J. Mar. Sys., 33-34:197-214.

Garreau, P., Garnier, V., and Schaeffer, A. (2011). Eddy resolving modelling of the Gulf of Lions ans Catalan Sea. Ocean Dynam., 61:991-1003. 
1 Gaspar, P., Grégoris, Y., and Lefevre, J.-M. (1990). A simple eddy kinetic energy model for simulations of the oceanic vertical mixing: Tests at Station Papa and long-term upper ocean study site. J. Geophys. Res., 95:179-193.

Gattuso, J.-P., Frankignoulle, M., and Wollast, R. (1998). Carbon and Carbonate Metabolism in Coastal Aquatic Ecosystems. Annu. Rev. Ecol. Syst., 29:pp. 405-434.

Grantham, B. A., Chan, F., Nielsen, K. J., Fox, D. S., Barth, J. A., Huyer, A., Lubchenco, J., and Menge, B. A. (2004). Upwelling-driven nearshore hypoxia signals ecosystem and oceanographic changes in the northeast Pacific. Nature, 429:749-754.

Griffa, A., Kirwan, A., Mariano, A. J., Özgökmen, T., and Rossby, H. T. (2007). Lagrangian Analysis and Prediction of Coastal and Ocean Dynamics. Cambridge University Press.

Gustafsson, Ö., Buesseler, K. O., Geyer, W. R., Moran, S. B., and Gschwend, P. M. (1998). An assessment of the relative importance of horizontal and vertical transport of particle-reactive chemicals in the coastal ocean. Cont. Shelf Res., 18(7):805-829.

Haller, G. (2011). A variational theory of hyperbolic Lagrangian Coherent Structures. Physica D, 240(7):574-598.

Haller, G. and Yuan, G. (2000). Lagrangian coherent structures and mixing in two-dimensional turbulence. Physica D, 147:352-370.

Haza, A. C., Özgökmen, T. M., Griffa, A., Molcard, A., Poulain, P.-M., and Peggion, G. (2010). Transport properties in small-scale coastal flows: relative dispersion from VHF radar measurements in the Gulf of La Spezia. Ocean Dyn., 60(4):861-882.

Haza, A. C., Poje, A. C., Özgökmen, T. M., and Martin, P. (2008). Relative dispersion from a high-resolution coastal model of the Adriatic Sea. Ocean Model., 22(1-2):48-65.

Holtermann, P. L., Umlauf, L., Tanhua, T., Schmale, O., Rehder, G., and Waniek, J. J. (2012). The Baltic Sea Tracer Release Experiment: 1. Mixing rates. J. Geophys. Res., $117(\mathrm{C} 1)$.

Hopkins, J., Sharples, J., and Huthnance, J. M. (2012). On-shelf transport of slope water lenses within the seasonal pycnocline. Geophys. Res. Lett., $39(8): 85-93$.

Hoskins, B. (1982). The mathematical theory of frontogenesis. Annu. Rev. Fluid Mech., 14:31-151.

Hu, Z. Y., Doglioli, A. M. Petrenko, A. A., Marsaleix, P., and Dekeyser, I. (2009). Numerical simulations of eddies in the Gulf of Lion. Ocean Model., 28(4):203- 208 .

Hu, Z. Y., Petrenko, A. A., Doglioli, A. M., and Dekeyser, I. (2011a). Numerical study of eddy generation in the western part of the Gulf of Lion. J. Geophys. Res., 116.

Hu, Z. Y., Petrenko, A. A., Doglioli, A. M., and Dekeyser, I. (2011b). Study of mesoscale anticyclonic eddy in the western part of the Gulf of Lion. J. Mar. Sys., 88:3-11. 
Huthnance, J. (1995). Circulation, exchange and water masses at the ocean margin: the role of physical processes at the shelf edge. Prog. Oceanogr., $35(4): 353-431$.

Huthnance, J. M., Holt, J. T., and Wakelin, S. L. (2009). Deep ocean exchange with west-european shelf seas. Ocean Sci., 5(4):621-634.

Huthnance, J. M., Van Aken, H. M., White, M., Barton, E. D., Le Cann, B., Ferreira Coelho, E., Alvarez Fanjul, E., Miller, P., and Vitorino, J. (2002). Ocean margin exchange-water flux estimates. J. Mar. Sys., 32(1-3):107 137.

Johnson, J. and Chapman, P. (2011). Preface "Deep Ocean Exchange with the Shelf (DOES)". Ocean Sci., 7(1).

Kersalé, M., Doglioli, A. M., Petrenko, A. A., Dekeyser, I., and Nencioli, F. (2013). Physical characteristics and dynamics of the coastal Latex09 Eddy derived from in situ data and numerical modeling. J. Geophys. Res., 118:111 .

Kersalé, M., Petrenko, A. A., Doglioli, A. M., Nencioli, F., Bouffard, J., Blain, S., Diaz, F., Labasque, T., Quéguiner, B., and Dekeyser, I. (2015). Lateral diffusivity coefficients from the dynamics of a SF6 patch in a coastal environment. J. Mar. Sys., 153:42-54.

Kirincich, A. R. and Barth, J. A. (2009). Time-varying across-shelf ekman transport and vertical eddy viscosity on the inner shelf. J. Phys. Oceanogr., 39(3):602.

Law, C., Watson, A., and Liddicoat, M. (1994). Automated vacuum analysis of sulphur hexafluoride in seawater: derivation of the atmospheric trend (1970-1993) and potential as a transient tracer. Mar. Chem., 48(1):57 - 69.

Ledwell, J. R. and Watson, A. J. (1991). The Santa-Monica Basin tracer experiment - A study of dyapycnal and isopycnal mixing. J. Geophys. Res., 96(C5):8695-8718.

Ledwell, J. R., Watson, A. J., and Law, C. S. (1998). Mixing of a tracer in the pycnocline. J. Geophys. Res., 103(C10):21499-21529.

Lehahn, Y., d'Ovidio, F., Lévy, M., and Heifetz, E. (2007). Stirring of the northeast atlantic spring bloom: A lagrangian analysis based on multisatellite data. J. Geophys. Res., 112(C08005).

Lévy, M., Ferrari, R., Franks, P. J., Martin, A. P., and Rivière, P. (2012). Bringing physics to life at the submesoscale. Geophys. Res. Lett., 39(14).

Lumpkin, R. and Elipot, S. (2010). Surface drifter pair spreading in the North Atlantic. J. Geophys. Res., 115.

MacFadyen, A. and Hickey, B. M. (2010). Generation and evolution of a topographically linked, mesoscale eddy under steady and variable wind-forcing. Cont. Shelf Res., 30(13):1387-1402.

MacFadyen, A., Hickey, B. M., and Cochlan, W. P. (2008). Influences of the Juan de Fuca Eddy on circulation, nutrients, and phytoplankton production in the northern California Current System. J. Geophys. Res., 113(C08008).

Mahadevan, A. (2016). The impact of submesoscale physics on primary productivity of plankton. Ann. Rev. Mar. Sci., 8(1):161-184. 
1 Mancho, A. M., Hernandez Garcia, E., Small, D., Wiggins, S., and Fernandez, V. (2008). Lagrangian transport through an ocean front in the northwestern Mediterranean sea. J. Phys. Oceanogr., 38(6):1222-1237.

Marsaleix, P., Auclair, F., and Estournel, C. (2006). Considerations on Open Boundary Conditions for Regional and Coastal Ocean Models. J. Atmos. Ocean. Technol., 23:1604-1613.

Marsaleix, P., Auclair, F., Floor, J., Herrmann, M., Estournel, C., Pairaud, I., and Ulses, C. (2008). Energy conservation issues in sigma-coordinate free-surface ocean models. Ocean Model., 20:61-89.

McWilliams, J. C., Brown, E. D., Bryden, H. L., Ebbesmeyer, C. C., Elliott, B. A., Heinmiller, R. H., Lien Hua, B., Leaman, K. D., Lindstrom, E. J., Luyten, J. R., McDowell, S. E., Breckner Owens, W., Perkins, H., Price, J. F., Regier, L., Riser, S. C., Rossby, H. T., Sanford, T. B., Shen, C. Y., Taft, B. A., and Van Leer, J. C. (1983). The Local Dynamics of Eddies in the Western North Atlantic, pages 92-113. Springer Berlin Heidelberg, Berlin, Heidelberg.

Melson, A., Meyers, S. D., Hurlburt, H. E., Metzger, E. J., and O'Brien, J. J. (1999). ENSO effects on Gulf of Alaska eddies. Earth Interactions 3, 003.

Millot, C. (1979). Wind induced upwellings in the Gulf of Lions. Oceanol. Acta, 2:261-274.

Millot, C. (1982). Analysis of upwelling in the Gulf of Lions - Hydrodynamics of semi-enclosed seas: Proceedings of the 13th International Liège Colloquium on Ocean Hydrodynamics., volume 34. Elsevier Oceanogr. Ser., Amsterdam, The Netherlands.

Millot, C. (1990). The Gulf of Lions' hydrodynamics. Cont. Shelf Res., 10:885894.

Millot, C. and Crépon, M. (1981). Inertial Oscillations on the Continental Shelf of the Gulf of Lions. J. Phys. Oceanogr., 11:639-657.

Millot, C. and Taupier-Letage, I. (2005). Additional evidence of LIW entrainment across the Algerian subbasin by mesoscale eddies and not by a permanent westward flow. Prog. Oceanogr., 66(2):231-250.

Millot, C. and Wald, L. (1980). The effect of Mistral wind on the Ligurian current near Provence. Oceanol. Acta, 3(4):399-402.

Mitchelson-Jacob, G. and Sundby, S. (2001). Eddies of Vestfjorden, Norway. Cont. Shelf Res., 21(16-17):1901-1918.

Moore II, T., Matear, R., Marra, J., and Clementson, L. (2007). Phytoplankton variability off the western australian coast: Mesoscale eddies and their role in cross-shelf exchange. Deep-Sea Res. II, 54(8-10):943-960.

Moutin, T. and Bonnet, S. (2015). OUTPACE cruise, RV L'Atalante, http://dx.doi.org/10.17600/15000900.

Nagai, T., Gruber, N., Frenzel, H., Lachkar, Z., McWilliams, J. C., and Plattner, G.-K. (2015). Dominant Role of Eddies and Filaments in the Offshore Transport of Carbon and Nutrients in the California Current System. J. Geophys. Res., 120.

Naudin, J. J., Cauwet, G., Chretiennot-Dinet, M.-J., Deniaux, B., Devenon, J.L., and Pauc, H. (1997). River discharge and wind influence upon particulate 
transfer at the land-ocean interaction: case study of the Rhône river plume. Estuar. Coast. Shelf S., 45(3):303-316.

Nencioli, F., d'Ovidio, F., Doglioli, A., and Petrenko, A. (2013). In situ estimates of submesoscale horizontal eddy diffusivity across an ocean front. J. Geophys. Res., 118(12):7066-7080.

Nencioli, F., d'Ovidio, F., Doglioli, A. M., and Petrenko, A. A. (2011). Surface coastal circulation patterns by in-situ detection of Lagrangian coherent structures. Geophys. Res. Lett., 38(L17604).

Nencioli, F., Kuwahara, V. S., Dickey, T. D., Rii, Y. M., and Bidigare, R. R. (2008). Physical dynamics and biological implications of a mesoscale eddy in the lee of Hawai'i : Cyclone Opal observations during E-FLUX III. DeepSea Res. II, 55(10-13):1252-1274.

Nencioli, F., Petrenko, A. A., and Doglioli, A. M. (2016). Diagnosing crossshelf transport along an ocean front: an observational case study in the Gulf of Lion. J. Geophys. Res., (121):7218-7243.

Nof, D. (1999). Strange encounters of eddies with walls. J. Mar. Res., $57(5): 739-761$.

Olascoaga, M. J., Rypina, I. I., Brown, M. G., Beron Vera, F. J., Kocak, H., Brand, L. E., Halliwell, G. R., and Shay, L. K. (2006). Persistent transport barrier on the West Florida Shelf. Geophys. Res. Lett., 33(22).

Petrenko, A. A. (2003). Variability of circulation features in the Gulf of Lion NW Mediterranean Sea. Importance of inertial currents. Oceanol. Acta, $26: 323-338$.

Petrenko, A. A. (2007). Latex00 cruise in the Gulf of Lion, RV Téthys II, http://dx.doi.org/10.17600/7450130.

Petrenko, A. A. (2008). Latex08 cruise in the Gulf of Lion, RV Téthys II, http://dx.doi.org/10.17600/8450140.

Petrenko, A. A. (2009). Latex09 cruise in the Gulf of Lion, RV Téthys II, http://dx.doi.org/10.17600/9450140.

Petrenko, A. A. (2010). Latex10 cruise in the Gulf of Lion, RV Téthys II, http://dx.doi.org/10.17600/10450150.

Petrenko, A. A., Dufau, C., and Estournel, C. (2008). Barotropic eastward currents in the western Gulf of Lion, northwestern Mediterranean Sea, during stratified conditions. J. Mar. Sys., 74(1-2):406-428.

Petrenko, A. A., Kersalé, M., Nencioli, F., Gatti, J., Doglioli, A. M., and Dekeyser, I. (2013). Coastal circulation in the Gulf of Lion, the influence of mesoscale processes on interregional exchanges. 40th CIESM Congress proceedings.

Petrenko, A. A., Leredde, Y., and Marsaleix, P. (2005). Circulation in a stratified and wind-forced Gulf of Lions, NW Mediterranean Sea: in situ and modeling data. Cont. Shelf Res., 25:7-27.

Pinardi, N. (2003). The Mediterranean ocean forcasting system : first phase of implementation (1998-2001). Ann. Geophys., 21:3-20.

Quéguiner, B. (2011). KEOPS 2 cruise, RV Marion Dufresne, http://dx.doi.org/10.17600/11200050. 
1 Reverdin, G., Morisset, S., Marié, L., Bourras, D., Sutherland, G., Ward, B., Salvador, J., Font, J., Cuypers, Y., Centurioni, L., Hormann, V., Koldziejczyk, N., Boutin, J., D’Ovidio, F., Nencioli, F., Martin, N., Diverres, D., Alory, G., and Lumpkin, R. (2015). Surface salinity in the North Atlantic subtropical gyre during the STRASSE/SPURS summer 2012 cruise. Oceanography, 28:114-123.

Robinson, A. R. (1983). Overview and Summary of Eddy Science, pages 3-15. Springer Berlin Heidelberg, Berlin, Heidelberg.

Roughan, M., Garfield, N., Largier, J., Dever, E., Dorman, C., Peterson, D., and Dorman, J. (2006). Transport and retention in an upwelling region: The role of across-shelf structure. Deep Sea Res. II, 53(25-26):2931-2955.

Ruiz, S., Pascual, A., Mahadevan, A., Claret, M., Olita, A., Troupin, C., Tintoré, J., Poulain, P., Tovar-Sánchez, A., Mourre, B., and Capet, A. (2016). Intense ocean frontogenesis inducing submesoscale processes and impacting biochemistry. 48th International Liège Colloquium on Ocean Dynamics, Liège, Belgium. oral pres.

Schaeffer, A., Molcard, A., Forget, P., Fraunié, P., and Garreau, P. (2011). Generation mechanisms for mesoscale eddies in the Gulf of Lions : radar observation and modeling. Ocean Dynam., 61:1587-1609.

Schroeder, K., Haza, A. C., Griffa, A., Özgökmen, T. M., Poulain, P. M., Gerin, R., Peggion, G., and Rixen, M. (2011). Relative dispersion in the Liguro-Provencal basin: From sub-mesoscale to mesoscale. Deep Sea Res. I, 58(3):209-228.

Shcherbina, A. Y., Sundermeyer, M. A., Kunze, E., D’Asaro, E., Badin, G., Birch, D., Brunner-Suzuki, A.-M. E. G., Callies, J., Kuebel Cervantes, B. T., Claret, M., Concannon, B., Early, J., Ferrari, R., Goodman, L., Harcourt, R. R., Klymak, J. M., Lee, C. M., Lelong, M.-P., Levine, M. D., Lien, R.-C., Mahadevan, A., McWilliams, J. C., Molemaker, M. J., Mukherjee, S., Nash, J. D., Özgökmen, T., Pierce, S. D., Ramachandran, S., Samelson, R. M., Sanford, T. B., Shearman, R. K., Skyllingstad, E. D., Smith, K. S., Tandon, A., Taylor, J. R., Terray, E. A., Thomas, L. N., and Ledwell, J. R. (2015). The LatMix Summer Campaign: Submesoscale Stirring in the Upper Ocean. Bull. Am. Met. Soc., 96(8):1257-1279.

Ssalto/Duacs User Handbook, C. N. E. S. (2010). (M)SLA and (M)ADT near-real time and delayed time products, CNES (Centre National d-Etudes Spatiales). Technical report. Ref. cLS-DOS-NT-06.034.

Staneva, J. V., Dietrich, D. E., Stanev, E. V., and Bowman, M. J. (2001). Rim current and coastal eddy mechanisms in an eddy-resolving Black Sea general circulation model. J. Mar. Sys., 31(1):137-157.

Suthers, I. M., Young, J. W., Baird, M. E., Roughan, M., Everett, J. D., Brassington, G. B., Byrne, M., Condie, S. A., Hartog, J. R., and Hassler, C. S. (2011). The strengthening East Australian Current, its eddies and biological effects - an introduction and overview. Deep-Sea Res. II, 58(5):538-546.

Tew Kai, E., Rossi, V., Sudre, J., Weimerskirch, H., Lopez, C., Hernandez Garcia, E., Marsac, F., and Garcon, V. (2009). Top marine predators track Lagrangian coherent structures. Proc. Natl. Acad. Sci. U. S. A., 106(20):8245- 
8250.

Thomas, L. N., Tandon, A., and Mahadevan, A. (2008). Submesoscale Processes and Dynamics, pages 17-38. American Geophysical Union.

4 Wanninkhof, R., Hitchcock, G., Wiseman, W. J., Vargo, G., Ortner, P. B., Asher, W., Ho, D. T., Schlosser, P., Dickson, M.-L., Masserini, R., et al. (1997). Gas exchange, dispersion, and biological productivity on the west Florida shelf: Results from a Lagrangian tracer study. Geophys. Res. Lett., 24(14):1767-1770.

Waugh, D. W. and Abraham, E. R. (2008). Stirring in the global surface ocean. Geophys. Res. Lett., 35(20). 